\title{
Measurements of global distributions of polar mesospheric clouds during 2005-2012 by MIPAS/Envisat
}

\author{
Maya García-Comas ${ }^{1}$, Manuel López-Puertas ${ }^{1}$, Bernd Funke ${ }^{1}$, Á. Aythami Jurado-Navarro ${ }^{1}$, Angela Gardini ${ }^{1}$, \\ Gabriele P. Stiller ${ }^{2}$, Thomas von Clarmann ${ }^{2}$, and Michael Höpfner ${ }^{2}$ \\ ${ }^{1}$ Instituto de Astrofísica de Andalucía, CSIC, Granada, Spain \\ ${ }^{2}$ Karlsruhe Institute of Technology, Institute for Meteorology and Climate Research, Karlsruhe, Germany \\ Correspondence to: M. López-Puertas (puertas@iaa.es)
}

Received: 4 February 2016 - Published in Atmos. Chem. Phys. Discuss.: 26 February 2016

Revised: 29 April 2016 - Accepted: 13 May 2016 - Published: 3 June 2016

\begin{abstract}
We have analysed MIPAS (Michelson Interferometer for Passive Atmopheric Sounding) infrared measurements of PMCs for the summer seasons in the Northern $(\mathrm{NH})$ and Southern (SH) hemispheres from 2005 to 2012. Measurements of PMCs using this technique are very useful because they are sensitive to the total ice volume and independent of particle size. For the first time, MIPAS has provided coverage of the PMC total ice volume from midlatitudes to the poles. MIPAS measurements indicate the existence of a continuous layer of mesospheric ice, extending from about $\sim 81 \mathrm{~km}$ up to about $88-89 \mathrm{~km}$ on average and from the poles to about $50-60^{\circ}$ in each hemisphere, increasing in concentration with proximity to the poles. We have found that the ice concentration is larger in the Northern Hemisphere than in the Southern Hemisphere. The ratio between the ice water content (IWC) in both hemispheres is also latitudedependent, varying from a $\mathrm{NH} / \mathrm{SH}$ ratio of 1.4 close to the poles to a factor of 2.1 around $60^{\circ}$. This also implies that PMCs extend to lower latitudes in the NH. A very clear feature of the MIPAS observations is that PMCs tend to be at higher altitudes with increasing distance from the polar region (in both hemispheres), particularly equatorwards of $70^{\circ}$, and that they are about $1 \mathrm{~km}$ higher in the SH than in the $\mathrm{NH}$. The difference between the mean altitude of the PMC layer and the mesopause altitude increases towards the poles and is larger in the NH than in the SH. The PMC layers are denser and wider when the frost-point temperature occurs at lower altitudes. The layered water vapour structure caused by sequestration and sublimation of PMCs is present at latitudes northwards of $70^{\circ} \mathrm{N}$ and more pronounced towards the pole. Finally, MIPAS observations have also shown a clear impact
\end{abstract}

of the migrating diurnal tide on the diurnal variation of the PMC volume ice density.

\section{Introduction}

Polar mesospheric clouds (PMCs), also called noctilucent clouds (NLCs), occur in the coldest regions of the atmosphere near the summer polar mesopause. PMCs normally form a layer extending vertically for several kilometres, peaking near $83 \mathrm{~km}$, located at latitudes polewards of $50^{\circ}$. In this region the temperature frequently drops below the frost point which, for mesospheric pressures and humidities, is about $150 \mathrm{~K}$. They mainly consist of water ice particles with radii ranging from a few $\mathrm{nm}$ to about $100 \mathrm{~nm}$ (Rusch et al., 1991; Gumbel and Witt, 1998; Hervig et al., 2001; von Savigny et al., 2005).

PMCs modify the ambient plasma of the D-region and gives rise to intense radar echoes, the so-called PMSE (polar mesospheric summer echoes) (Rapp and Lübken, 2004). It is now generally accepted that larger ice particles are located near the bottom of the layer, while smaller ones are more likely to be near the top of the layer (Berger and Zahn, 2002; von Savigny et al., 2005; Baumgarten and Fiedler, 2008).

PMCs have been intensively studied using ground, rocket, and space observations using SNOE/UVS (Student Nitric Oxide Explorer/Ultraviolet Spectrometer, SBUV (Solar Backscatter Ultraviolet), Odin/OSIRIS (Optical Spectrograph and InfraRed Imager System), Envisat/SCIAMACHY (SCanning Imaging Absorption SpectroMeter for Atmospheric CHartographY), GOMOS (Global Ozone Monitor- 
ing by Occultation of Stars), AIM/SOFIE (Aeronomy of Ice in the Mesosphere/Solar Occultation For Ice Experiment), and AIM/CIPS (Cloud Imaging and Particle Size). (e.g. Baumgarten and Fiedler, 2008; Fiedler et al., 2009; Gumbel and Witt, 1998; Bailey et al., 2005; DeLand et al., 2003; Petelina et al., 2006; von Savigny et al., 2005, 2007; von Savigny and Burrows, 2007; Pérot et al., 2010; Russell III et al., 2009); as well as sophisticated models (e.g. Berger and Zahn, 2002; Berger and von Zahn, 2007). A good review of our knowledge on PMCs up until 2006 was compiled by Rapp and Thomas (2006). A more recent review, including a comparison with mesospheric clouds on Mars, was conducted by Määttänen et al. (2013).

PMCs are being discussed as potential early indicators of global climate change in the middle atmosphere (Thomas et al., 1989; von Zahn, 2003) because they are very sensitive to temperature and water vapour concentration. Since enhanced $\mathrm{CO}_{2}$ amounts (see, e.g. Yue et al., 2015) are expected to lead to an eventual cooler upper mesosphere/lower thermosphere, and higher $\mathrm{CH}_{4}$ amounts to enhanced $\mathrm{H}_{2} \mathrm{O}$ near the mesopause (Roble and Dickinson, 1989; Nedoluha et al., 2009; Garcia et al., 2015), they may both lead to an increase of PMC occurrence, which might be interpreted as an effect of climate change in the middle atmosphere. There is not, however, a consensus in the scientific community about this aspect (von Zahn, 2003; Thomas, 2003). The recent study of SBUV data from 1979 to 2013 by DeLand and Thomas (2015) has shown, in addition to the clear solar cycle signal, a good correlation with stratospheric ozone variations. Also, they have found that PMC ice water content in bright clouds increased rapidly from 1979 to the late 1990s and has been approximately constant from the late 1990s to 2013. Similar results were found by Hervig and Stevens (2014) using SBUV data and a different method for calculating the ice water content (IWC). These authors also compared SBUV and SOFIE data and found good agreement in average IWC if an appropriate threshold was applied to the SOFIE data set and consistent day-to-day and year-to-year variations between both data sets were used.

Russell et al. (2014) looked at trends in the northern midlatitude noctilucent cloud occurrences using satellite data and model simulations and found a significant increase in the PMC occurrences at midlatitudes from 2002 to 2011. This result differs somewhat from the insignificant trend found by DeLand and Thomas (2015) for a similar period but at higher latitudes.

Berger and Lübken (2015) analysed trends in mesospheric ice layers in the high-latitude Northern Hemisphere for the 1961-2013 period with model simulations. They reported a generally good agreement between long-term PMC variations from the MIMAS model and the SBUV satellite observations. They found that the modelled trends in ice water content are latitudinally dependent with no clear trend at midlatitudes $\left(50-60^{\circ} \mathrm{N}\right)$ but with a clear positive trend at high latitudes $\left(74-82^{\circ} \mathrm{N}\right)$ and also in extreme PMC events.
Thomas et al. (2015) studied the solar-induced 27-day variations in polar mesospheric clouds using 15 seasons of SOFIE data and suggested that the 27-day variations in the PMCs are due to 27-day variations of vertical winds.

As described above, a large fraction of the observations taken so far were performed by measuring the scattered light, in the visible or UV, of the solar radiation (in the case of instruments from space) or lidar light (in case of ground instruments). This technique usually observes the ice particles with radii larger than about $20 \mathrm{~nm}$ but lacks sensitivity for smaller particles (see, e.g. Rapp and Thomas, 2006). A different technique, however, has been developed recently by the AIM/SOFIE instrument. These measurements have provided key characteristics of PMCs such as their frequency, mass density, particle shape, and size distribution, as well as their seasonal evolution and altitude dependence (see, e.g. Hervig et al., 2009a, b, 2011, 2013). Furthermore these satellite data have supplied critical information about the relationship of the ice density distribution with mesopause temperature and water vapour concentration (see, e.g. Hervig et al., 2009c; Russell et al., 2010; Hervig et al., 2015).

While PMCs emit thermal radiation, their infrared (IR) emissions are very difficult to observe due to the low ice particle volume density and the very cold polar summer mesopause temperatures. In fact, only three IR emission observations have been reported to date: those taken by CRISTA (Grossmann et al., 2006), by SPIRIT (O'Neil et al., 2008) and those taken by the Michelson Interferometer for Passive Atmospheric Sounding (MIPAS) (López-Puertas et al., 2009). This technique has the advantages of being able to measure PMCs in dark conditions, thus providing a better spatial and temporal coverage, and of being sensitive to the total ice volume density, regardless of particle size, and hence include the very small particles.

In a previous paper López-Puertas et al. (2009) reported the detection of infrared emissions from PMCs taken by the MIPAS instrument on board Envisat (Environmental Satellite), and provided further evidence of the water ice nature of the PMC particles. We also described the retrieval of the ice particle volume density and reported the analysis of the retrieved densities for 19-21 July 2005. In this paper we present the global distribution (by altitude, latitude, and longitude) of ice volume density measured by MIPAS for several days in each of the Northern $(\mathrm{NH})$ and Southern Hemisphere (SH) seasons from 2005 to early 2012. We also analyse several aspects of the PMCs such as (i) the mean altitude of the layer, the ice water content and its hemispheric dependence; (ii) the correlation of ice volume density with the frost-point temperature and the water vapour concentration; and (iii) the diurnal variation of the ice volume density. MIPAS, as well as SOFIE, has the advantage of measuring the whole content of ice particles (all sizes) in the mesosphere. Hence, a comparison with SOFIE observations, version 1.3, is also shown. 
Table 1. Days of MIPAS observations of PMCs in the different modes.

\begin{tabular}{|c|c|}
\hline Mode & Days \\
\hline NLC & $\begin{array}{l}200507192005072020050721200707042007070520070714200707152008070520080706 \\
200807072009010520090106200901072009070520090706200907072010010420100105 \\
201001062010070320100704201007052011010920110110201101112011070820110709 \\
20110710201201042012010520120106\end{array}$ \\
\hline MA & $\begin{array}{l}200501102005011120050112200501132005122920051230200606212006062220061219 \\
200612202006122120070622200707252007080420071219200712292008010820080116 \\
200801262008020520080616200806252008071520080725200808042008122220090101 \\
200901112009020520090615200906252009071520090725200908012009081120091215 \\
200912252010011420100122201006132010062320100713201007232010080220100812 \\
2011011920110618201106282011071920110801201108072011122520120114\end{array}$ \\
\hline UA & $\begin{array}{l}200501212005012220050722200512312006062320061222200706202007062120071220 \\
200712302008010920080117200801272008020620080622200807162008072620080805 \\
200812232009010220090112200901192009012020090206200906162009062620090716 \\
200907262009080220090812200912202009123020100109201001172010061820100628 \\
201007182010072820100807201008172010122520110104201101142011012420110130 \\
201101312011020120110623201107032011071420110727201108042011081220111220 \\
201112302012010920120124\end{array}$ \\
\hline
\end{tabular}

\section{MIPAS measurements and ice density retrieval}

MIPAS is a high-resolution limb sounder on board the Envisat satellite, launched on 1 March 2002. It took measurements until 8 April 2012, when the Envisat satellite failed. MIPAS measurements covered a wide spectral range with a high spectral resolution, operating at $0.025 \mathrm{~cm}^{-1}$ from 2002 to 2004 and $0.0625 \mathrm{~cm}^{-1}$ from 2005 to the end of the mission. It also operated with a high sensitivity, allowing measurements of most of the atmospheric emissions in the midinfrared over a large altitude range (Fischer et al., 2008). MIPAS operated with a global latitudinal coverage (poleto-pole) and performed measurements irrespective of dayor night-time. The instrument carried out most of its observations in the 6-68 km altitude range (the nominal mode), but it also regularly made observations at higher altitudes in its middle-atmosphere (MA), noctilucent cloud (NLC), and upper-atmosphere (UA) modes (De Laurentis, 2005; Oelhaf, 2008).

In the MA mode, the spectra are available at limb tangent heights from about 20 up to $102 \mathrm{~km}$ with a vertical sampling of $3 \mathrm{~km}$. The UA mode ranges from about 42 to $172 \mathrm{~km}$, and has a vertical sampling of 3 up to $102 \mathrm{~km}$, and $5 \mathrm{~km}$ above this altitude. The NLC mode is a variant of the MA mode specifically tailored for measuring the PMCs during the summer seasons (De Laurentis, 2005; Oelhaf, 2008). In this mode the spectra cover tangent heights from 39 up to $78 \mathrm{~km}$ at $3 \mathrm{~km}$ steps; then from 78 up to $87 \mathrm{~km}$ at $1.5 \mathrm{~km}$ steps, and from 87 up to $102 \mathrm{~km}$ again in $3 \mathrm{~km}$ steps. The horizontal field of view (FOV) of MIPAS is approximately $30 \mathrm{~km}$. The days of PMC measurements in the different observation modes are listed
Table 2. Distribution of MIPAS days of observation of PMCs per season*

\begin{tabular}{c|cc|cc|cc|cc}
\hline & \multicolumn{2}{|c|}{ NLC } & \multicolumn{2}{c|}{ MA } & \multicolumn{2}{c|}{ UA } & \multicolumn{2}{c}{ Total } \\
Year & NH & SH & NH & SH & NH & SH & NH & SH \\
\hline 2005 & 3 & - & - & 4 & 1 & 2 & 4 & 6 \\
2006 & - & - & 2 & 2 & 1 & 1 & 3 & 3 \\
2007 & 4 & - & 3 & 3 & 2 & 1 & 9 & 4 \\
2008 & 3 & - & 5 & 6 & 4 & 6 & 12 & 12 \\
2009 & 3 & 3 & 6 & 4 & 6 & 6 & 15 & 13 \\
2010 & 3 & 3 & 6 & 4 & 6 & 4 & 15 & 11 \\
2011 & 3 & 3 & 5 & 1 & 6 & 7 & 14 & 11 \\
2012 & - & 3 & - & 2 & - & 4 & - & 9 \\
Total & 19 & 12 & 27 & 26 & 26 & 31 & 72 & 69 \\
\hline
\end{tabular}

* For the NH season the days correspond to June-August of the listed year. For $\mathrm{SH}$ season the days correspond to December of the preceding year and January-February of the listed year.

in Table 1, and a summary of the distribution of these days within the different seasons is shown in Table 2.

The method used for the retrieval of PMC ice volume density from the MIPAS spectra has been described by LópezPuertas et al. (2009). A brief excerpt is included here. The spectra analysed in this work were all taken with the optimized spectral resolution of $0.0625 \mathrm{~cm}^{-1}$. The ice volume density was retrieved from the radiance profiles obtained by integrating the spectra from 770 to $920 \mathrm{~cm}^{-1}$. The profiles were corrected for an offset variable in altitude, latitude, and time. The noise equivalent spectral radiance in this spectral region is about $20 \mathrm{nW} /\left(\mathrm{cm}^{2} \mathrm{srcm}^{-1}\right)$, and the corresponding noise in the integrated radiances of a single scan is $\sim 60 \mathrm{nW} /\left(\mathrm{cm}^{2} \mathrm{sr}\right)$. 
The ice volume density was retrieved from the spectrally integrated radiance profiles using a linearly constrained least squares fitting, where the Jacobians were calculated using the Karlsruhe Optimized and Precise Radiative transfer Algorithm (KOPRA) radiative transfer algorithm (Stiller et al., 2002). The inversion was constrained by a Tikhonov-type scheme (Tikhonov, 1963) using a squared first-order differences matrix to obtain a reasonably smoothed vertical profile of volume densities. The ice refractive indices were taken from Toon et al. (1994).

In this analysis we have included the following improvements and updates with respect to López-Puertas et al. (2009): (i) The more recent version 5 (5.02/5.06) of MIPAS L1b spectra has been used (Perron et al., 2010; Raspollini et al., 2010); (ii) an updated version of the temperature is used for the retrieval of ice density (see below); (iii) the altitude registration of the $\mathrm{L} 1 \mathrm{~b}$ spectra has been improved using the information from the retrieved temperature and LOS (line of sight) instead of the engineering information included in the L1b files (von Clarmann et al., 2003; García-Comas et al., 2012a); (iv) the offset correction of the integrated radiance profiles was improved by taking into account its altitude and latitudinal variations; (v) the ice density profiles were retrieved only for scans with converged pressure-temperature profiles (no interpolation over latitude/longitude was done); and (vi) due to a mistake in the calculation of the volume of the particles distribution, the volume densities presented here are nearly double those previously reported by LópezPuertas et al. (2009).

The temperature and LOS required to retrieve the ice density have been retrieved from the $\mathrm{CO}_{2}$ emission near $15 \mu \mathrm{m}$, recorded in the same MIPAS band A as the PMC emission. Non-local thermodynamic equilibrium (non-LTE) emissions were taken into account. The detailed description of the method and the characterization of the inverted temperature profiles are described by García-Comas et al. (2012a). The upgrades in the retrieval of the temperature used here (version vM21) and a validation of the results are reported by García-Comas et al. (2014). Briefly, these authors include an updated version of the calibrated L1b spectra in the $15 \mu \mathrm{m}$ region (versions 5.02/5.06); the HITRAN (HIgh-resolution TRANsmission molecular absorption) 2008 database for $\mathrm{CO}_{2}$ spectroscopic data; the use of a different climatology of atomic oxygen and carbon dioxide concentrations; the improvement of several aspects of the retrieval set-up (temperature gradient along the line of sight, offset regularization, and the spectral apodization); and some minor corrections to the $\mathrm{CO}_{2}$ non-LTE modelling as detailed by Funke et al. (2012). This version of MIPAS temperatures corrects the main systematic errors of the previous version and show, in general, a remarkable agreement with the measurements taken by ACE-FTS Fourier transform spectrometer, MLS (Microwave Limb Sounder), Odin-OSIRIS, TIMED-SABER (Thermosphere Ionosphere Mesosphere Energetics Dynamics - Sounding of the Atmosphere using Broadband Emis- sion Radiometry), AIM-SOFIE, and the Rayleigh lidars at Mauna Loa and Table Mountain (García-Comas et al., 2014). In the region of interest here, however, there are still significant differences, with MIPAS polar summer mesopause temperatures differing by $5-10 \mathrm{~K}$ from the other instruments, being warmer than SABER, MLS, and OSIRIS and colder than ACE-FTS and SOFIE.

Since MIPAS measures PMCs in IR emission, knowledge of the temperature of the ice particles is crucial. There is still disagreement on the temperature of the particles, particularly on whether they are warmer or colder than the ambient atmosphere. Using SOFIE measurements, Hervig and Gordley (2010) have found that the ice particles are about 5-20 K cooler than the ambient atmosphere. They suggested, however, that the V1.022 SOFIE $\mathrm{CO}_{2}$ temperatures they used might have a warm bias of 5-10 K near the polar summer mesopause. Petelina and Zasetsky (2009), using infrared solar occultation measurements from the ACE instrument, also found that the ice particles are cooler than the ambient temperature. They argue that this might be caused by inhomogeneities in the temperature along the instrument field of view, with the ice particles sensing only the cold(er) parcels where they are present, while the gas temperature is representative of the whole (warmer) air mass along the FOV. Physical considerations, however, would suggest that the particles are warmer than the surrounding gas because they are heated by absorption of radiation (Rapp and Thomas, 2006; Espy and Jutt, 2002). For example, for a particle distribution with a mean radius between 30 and $50 \mathrm{~nm}$ and an accommodation coefficient of 0.5, Rapp and Thomas (2006) found that the ice particles are warmer than the ambient gas by about $1 \mathrm{~K}$ at $80 \mathrm{~km}$ and $2 \mathrm{~K}$ at $90 \mathrm{~km}$. Analogously, the model calculation of Espy and Jutt (2002), when applied to a normal distribution of ice particle size with a mean radius varying from $40 \mathrm{~nm}$ at $80 \mathrm{~km}$ to $15 \mathrm{~nm}$ at $90 \mathrm{~km}$, gives a temperature increase of $0.7 \mathrm{~K}$ at $80 \mathrm{~km}$ and $2.7 \mathrm{~K}$ at $90 \mathrm{~km}$. As suggested by these models, we applied a temperature correction of the emitting particles that varies linearly from $1 \mathrm{~K}$ at $80 \mathrm{~km}$ to $2 \mathrm{~K}$ at $90 \mathrm{~km}$. In principle, MIPAS measurements should also be affected by the problem pointed out by Petelina and Zasetsky (2009). However, our observations do not support that finding. If we assume that ice particles are cooler than the retrieved gas temperature we obtain very high (and unreasonable) concentrations of ice particles (see Sect. 3).

The vertical resolution of the ice density profiles, in terms of the half-width of the columns of the averaging kernel matrix, depends on the observational mode. For the oversampled NLC mode, it varies from $\sim 2.5 \mathrm{~km}$ at $81-82 \mathrm{~km}$ to $\sim 3 \mathrm{~km}$ at $86 \mathrm{~km}$, and to $3.5-4 \mathrm{~km}$ at $90 \mathrm{~km}$. For the middle- and upper-atmosphere modes (MA and UA, or together MUA), it is coarser, with values ranging from 3.5 to $4 \mathrm{~km}$. The error in the absolute pointing is about $200 \mathrm{~m}$. The averaging kernels shown in López-Puertas et al. (2009) are for the NLC mode measurements that have a sampling step (i.e. tangent altitude increment) of $1.5 \mathrm{~km}$. For the MA and 

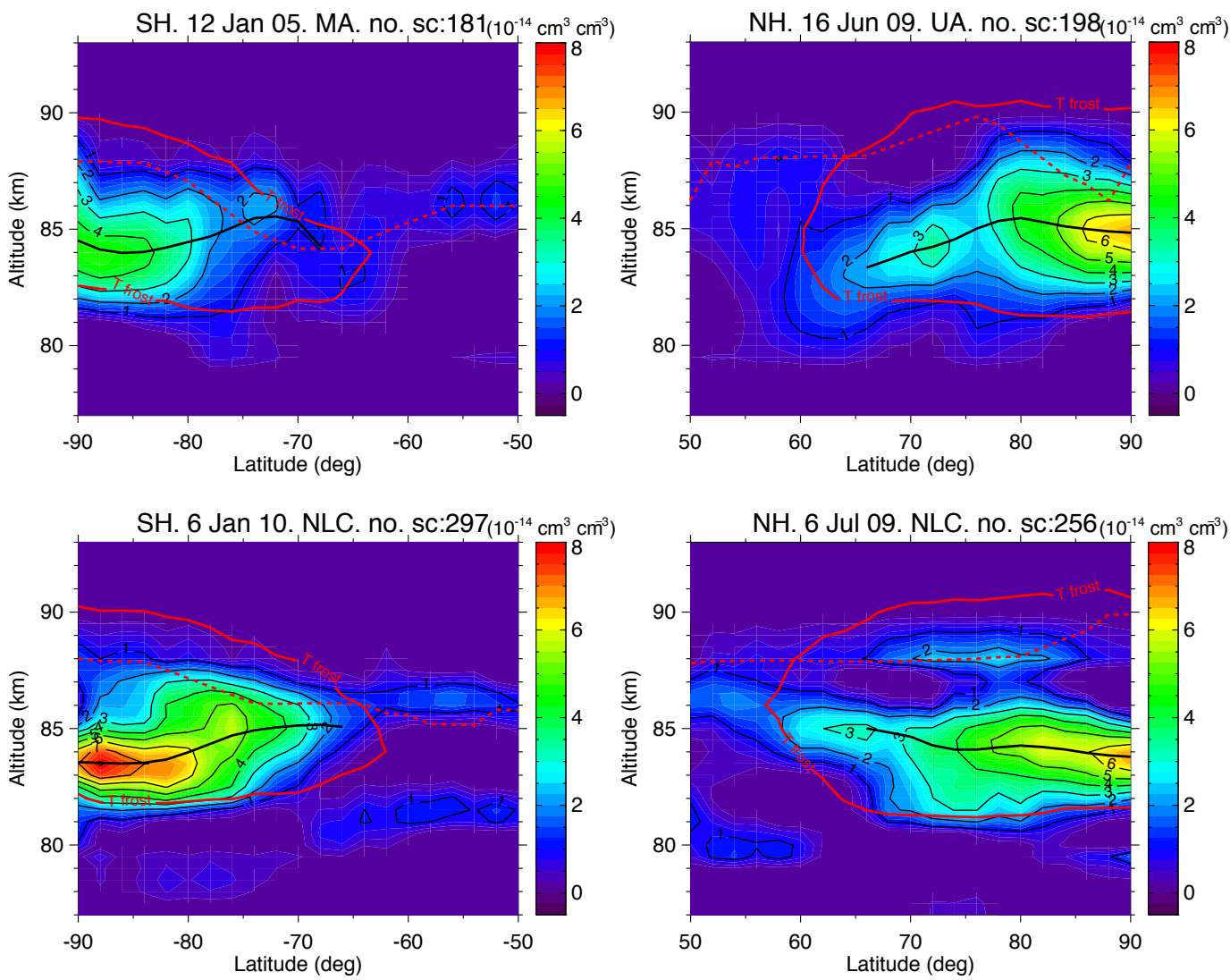

Figure 1. Zonal mean ice volume density during four days, two in the $\mathrm{SH}$ and two in the NH, as measured by MIPAS in different observation modes (MA, UA, and NLC, see labels). The solid red lines indicate the frost-point temperature. The red dashed line is the mesopause as derived from MIPAS. The black solid line is an estimated mean altitude (weighted with the ice density to power of 4) of the PMC layer. The number of measured profiles, "\#sc", is also shown. The noise error of the mean volume density plotted here, estimated by the standard error of the mean, is about $0.3 \times 10^{-14} \mathrm{~cm}^{3} \mathrm{~cm}^{-3}$.

UA modes the averaging kernels are wider because of the coarser sampling of $3 \mathrm{~km}$.

The random single-profile error of the retrieved ice volume density is about $60 \%$, including both the instrumental noise and the temperature noise error. The systematic error is about $25-30 \%$ and is mainly due to the temperature error in the summer mesopause region (García-Comas et al., 2014). More details of the retrieval of the ice volume density can be found in López-Puertas et al. (2009).

\section{Ice volume density distributions}

Figure 1 shows typical daily zonal means of ice volume density retrieved from MIPAS for four days in SH and NH summer seasons in different observation modes. The thick solid red line is the frost-point temperature contour, and the red dashed line is the mesopause altitude. The solid black line is an estimated altitude of the PMC layer (i.e. the altitude weighted with the 4 th power of the density). Note that MIPAS is sensitive to all ice particles, including those with a small radius. Noise errors in these plots, estimated by the standard error of the mean, are about $0.3 \times 10^{-14} \mathrm{~cm}^{3} \mathrm{~cm}^{-3}$. The PMCs are generally located at regions colder than the frost-point temperature for almost all conditions. Note also the large variability in latitude and altitude of the ice density, particularly on 6 July 2009 (bottom right panel), where the PMCs reach latitudes as low as $60^{\circ} \mathrm{N}$. Weak PMCs located at latitudes equatorwards of about $60^{\circ}$ and outside of the frostpoint temperature contour are likely false detections caused by instrumental (most likely offset) errors.

Anomalous low-altitude detection of weak PMCs (i.e. below $\sim 80 \mathrm{~km}$ and outside of the $T_{\text {frost }}$ region) could be due to the limb nature of the measurements. Emissions from isolated clouds located in the LOS far away from the tangent point are reported at abnormally low tangent altitudes (see, e.g. Hervig et al. (2009b), their Fig. 11). Also, the FOV can affect the height of the lower and upper boundaries of the layer. Hervig et al. (2009b) have shown that the bottom and top altitudes as measured by SOFIE, which has a FOV of $1.5 \mathrm{~km}$, can be smeared out in about $1-1.5 \mathrm{~km}$. These two effects, along with the temperature error, can explain why MIPAS observes occasional ice volume concentration at the 

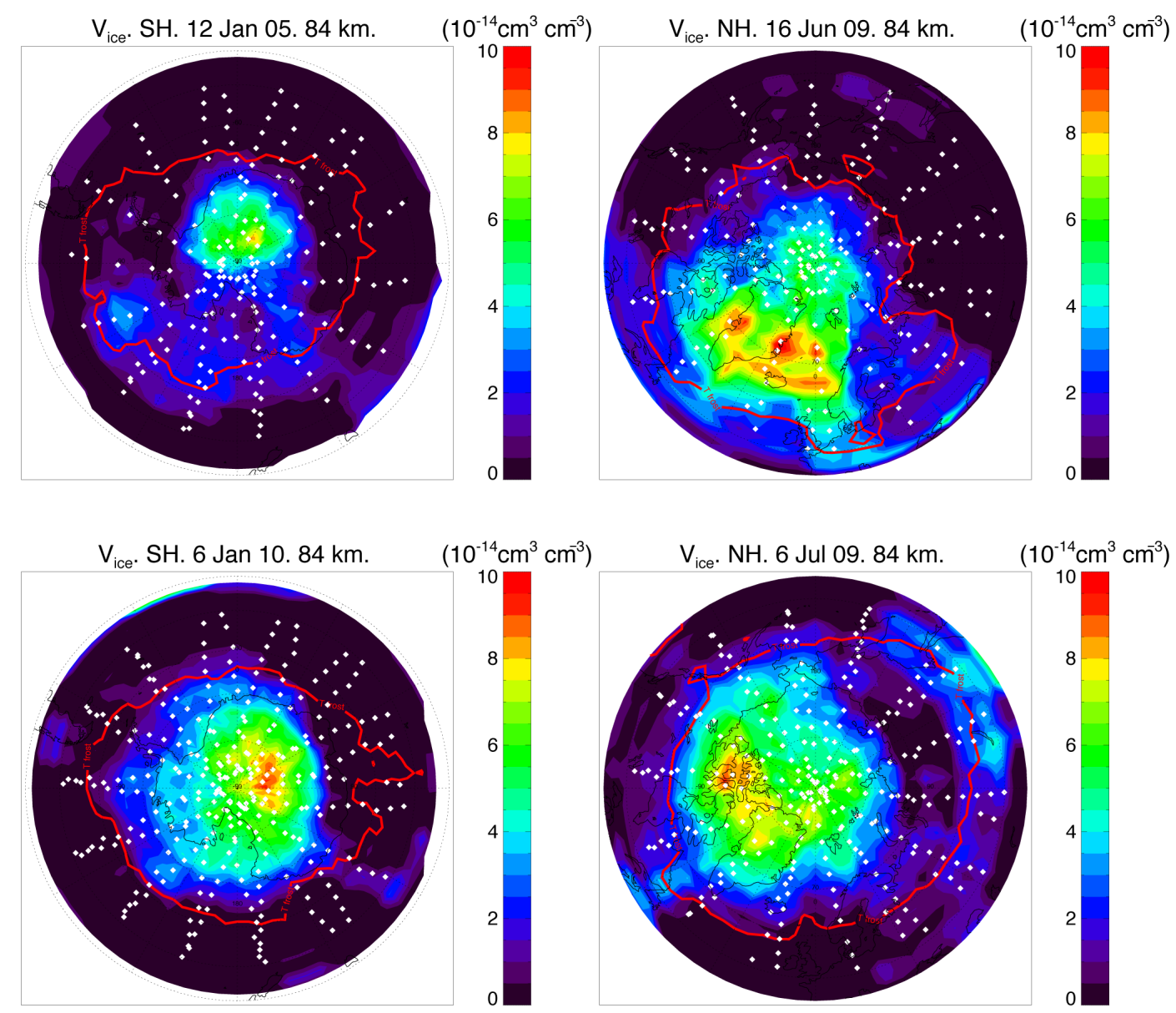

Figure 2. Polar maps of ice volume density at $84 \mathrm{~km}$ for the same days as in Fig. 1. The solid red lines indicate the frost-point temperature. The diamonds represent the geolocations of the MIPAS measurements.

bottom of the layer at temperatures warmer than the frostpoint temperature.

The latitudinal and longitudinal distributions of ice volume density at $84 \mathrm{~km}$ for corresponding days are shown in Fig. 2. As shown before for the zonal means, the PMC layer is almost always confined to regions with temperature below the frost-point temperature. The variability of the latitudinal and longitudinal spread is also large. Although the PMCs are generally around the pole, they are sometimes far away (see top right panel in Fig. 2) and their distribution could be controlled by 2-day and/or 5-day planetary waves (Merkel et al., 2003, 2009; Nielsen et al., 2010). In particular the distributions of the days 12 January 2005 (top/left), 16 January 2009 (top/right), and 6 July 2009 (bottom/right) seem to be affected by wavenumber-1 planetary waves.

Figure 3 shows the zonal mean ice volume density averaged for all measured days in the Southern (left) and Northern (right) hemispheres for the NLC (top panels) and for the MA+UA (MUA) (lower panels) MIPAS modes (see Table 2). These distributions are analysed in detail later, but we describe the main features briefly here: (1) PMCs are confined to altitudes between around $81 \mathrm{~km}$ and $89 \mathrm{~km}$ with maximum concentrations around $84 \mathrm{~km}$; (2) PMCs are confined to latitudes polewards of about $60^{\circ}$, with increasing concentration towards the poles; and (3) from these figures it is evident that the ice particles occur in higher concentrations in the $\mathrm{NH}$ and that the ice layer is located at slightly lower altitudes in the NH. These figures also show an apparent higher concentration for the measurements taken in the NLC mode than in the MUA mode. The NLC mode has a better vertical resolution, which leads to sharper temperature profiles (see García-Comas et al., 2014) and hence to sharper ice particle profiles and larger ice particle densities. However, not all the differences between the NLC and the MUA modes can be attributed to the better vertical resolution of the former because observations in different modes occurred on different days, with observations in the NLC mode generally occurring closer in time to the peak of the PMC season than observations in the other modes. 

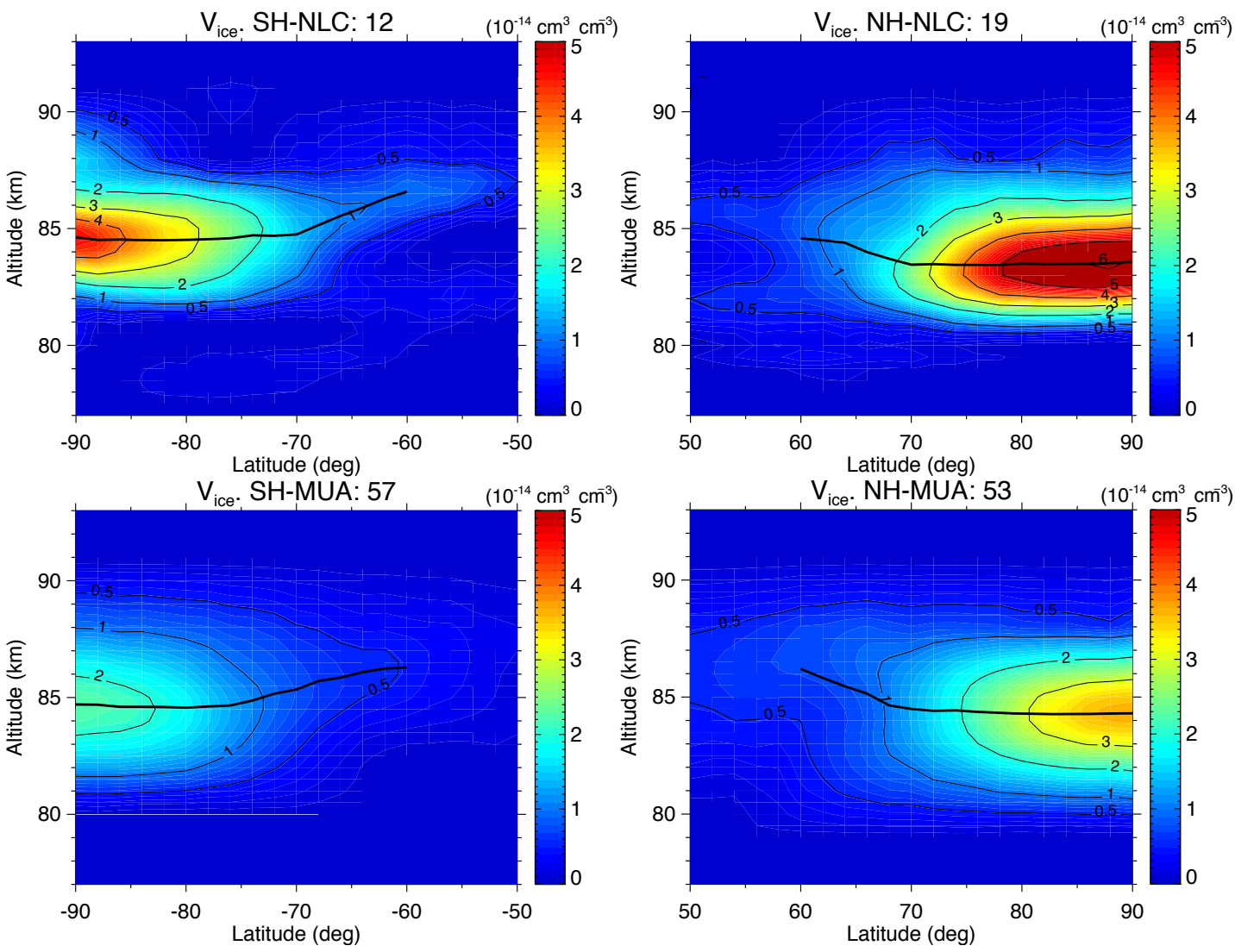

Figure 3. Zonal mean ice volume density for all measured days in the Southern (left panels) and Northern (right panels) hemispheres for the NLC (top panels) and the MUA (lower panels) MIPAS modes (see Table 2). The solid black line is an estimated mean altitude (weighted with the ice volume density to power of 4) of the PMC layer. The noise error of the volume density plotted here, estimated by the standard error of the mean, is about 0.08 and $0.04 \times 10^{-14} \mathrm{~cm}^{3} \mathrm{~cm}^{-3}$ for the NLC and MUA measurements, respectively.

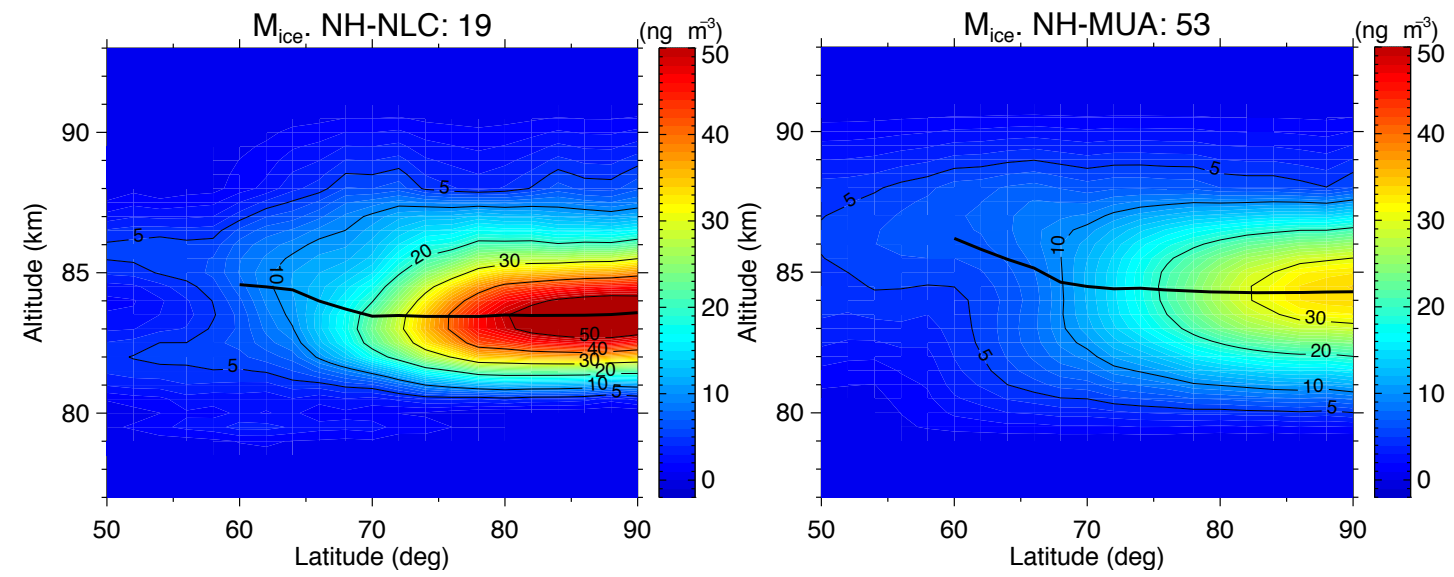

Figure 4. Zonal mean ice mass density for the NLC (left panel) and for the MA and UA (MUA) (right panel) MIPAS modes (see Table 2) for the Northern Hemisphere. The solid black line is an estimated mean altitude (weighted with the ice volume density to the 4th power) of the PMC layer. The noise error of the mass density plotted here, estimated by the standard error of the mean, is about 0.8 and $0.4 \mathrm{ng} \mathrm{m}^{-3}$ for the NLC and MUA measurements, respectively.

\subsection{Top altitude}

Figure 3 shows that MIPAS observes significant abundances of ice up to about $88-89 \mathrm{~km}$. A similar behaviour has been 
found in the SOFIE measurements (Hervig et al., 2009b). This altitude is about $3-4 \mathrm{~km}$ higher than the average maximum altitude of $84.4 \mathrm{~km}$ measured by the lidars (Hervig et al., 2009b). These authors have shown that, for SOFIE measurements, the vertical smoothing due to limb-viewing geometry can cause an extension of the uppermost altitude of about $2 / 3$ of the vertical resolution, i.e. $1.5-2 \mathrm{~km}$ for the MIPAS NLC observation mode. This, however, cannot fully explain that difference. The detection of PMCs by SOFIE and MIPAS at altitudes higher than the lidars is most likely due to the different sensitivities of the two techniques. While the lidar signal varies with $r^{6}$, the MIPAS (in IR emission) and SOFIE (in IR extinction) signals change with the total ice volume density. As the ice particle size decreases towards higher altitudes (Baumgarten and Fiedler, 2008; Hervig et al., 2009b; Pérot et al., 2010), MIPAS and SOFIE are then more sensitive than lidars to clouds at higher altitudes. The highest altitude of PMCs derived from MIPAS NLC mode measurements is largely variable, as can be seen in the typical examples shown in Fig. 1 . At $70^{\circ} \mathrm{N}$, it is about $88.5 \mathrm{~km}$ (Fig. 3b). Its variability depends on latitude and takes $1-\sigma$ values from $2.7 \mathrm{~km}$ near $70^{\circ} \mathrm{N}$ to $1.6 \mathrm{~km}$ near the pole. The uppermost altitude derived here is slightly higher than that obtained by SOFIE of $86.8 \pm 2.1 \mathrm{~km}$ but agrees very well with the Community Aerosol and Radiation Model for Atmospheres (CARMA) model prediction of $88.5 \pm 0.5 \mathrm{~km}$ (Hervig et al., 2009b, 2013). Thus, as pointed out by LópezPuertas et al. (2009) and Hervig et al. (2009b), MIPAS and SOFIE results are consistent with the current understanding of temperatures and water vapour distributions at these altitudes (Lübken, 1999), and the associated ice particles at high altitudes are likely to be related to polar mesosphere summer echoes (e.g. Rapp and Lübken, 2004). This has also been evidenced more recently by the concurrent observations from the Arctic Lidar Observatory for Middle Atmosphere Research (ALOMAR) wind (ALWIN) radar and SOFIE measurements (Hervig et al., 2011).

\subsection{Bottom altitude}

The bottom altitude of the PMC layers measured by the lidar measurements at $69^{\circ} \mathrm{N}$ was found at $82.2 \mathrm{~km}$. SOFIE obtained a slightly lower altitude of $81.6 \pm 1.6 \mathrm{~km}$, which is within the lidar and SOFIE combined standard deviations (Hervig et al., 2009b). For the NH and similar latitudes MIPAS in its NLC mode (see Fig. 3b) measured an altitude of $80.9 \pm 1.2 \mathrm{~km}$, slightly lower than SOFIE. In SOFIE measurements the PMCs with a peak extinction altitude below $79 \mathrm{~km}$ were excluded (Hervig et al., 2009b). Applying a similar threshold to MIPAS data, however, does not change significantly the bottom altitude.

The bottom altitude also changes rapidly with latitude from 65 to $75^{\circ}$ (Fig. 3b); hence a difference of a few degrees in latitude might induce a significant change in bottom altitude. Thus, in summary, we can conclude that they are in good agreement. It is also worth noting that the bottom altitude derived from the MUA modes, which have a coarser vertical sampling $(3 \mathrm{~km})$, is lower by about $1 \mathrm{~km}(80.0 \pm 1.8 \mathrm{~km})$ than that derived from the NLC mode (Fig. 3d). This is very likely due to the limb-sounding geometry, as discussed above. The bottom altitude in the Southern Hemisphere is found to be located at about $1 \mathrm{~km}$ higher than in the $\mathrm{NH}$ (see Figs. 3a and c).

\subsection{Ice mass density}

As discussed above, MIPAS and SOFIE are the only two instruments with comparable ice concentration data because they both measure the total ice volume density, irrespective of the ice crystal size. Although it is not the aim of this paper to carry out a detailed comparison or validation, we include some comparisons here. First, we compare the maximum (peak) values of the PMC layer, then we compare mean profiles for several seasons.

SOFIE measured ice mass densities at the altitude of maximum concentration, $z_{\max }$, for the $2007 \mathrm{NH}$ season that ranges from 0.1 to $80 \mathrm{ng} \mathrm{m}^{-3}$ with a mean value of $14.2 \mathrm{ng} \mathrm{m}^{-3}$ (Fig. 14a and Table 5 in Hervig et al., 2009b). These SOFIE measurements occurred at latitudes between $\sim 66^{\circ} \mathrm{N}$ in the early season and $\sim 68^{\circ} \mathrm{N}$ at mid-summer, and at $\sim 74^{\circ} \mathrm{N}$ towards the end of the season. MIPAS measurements for the 2005-2012 period at latitudes of \pm 2 degrees of SOFIE latitudes have mean values of just above $20 \mathrm{ng} \mathrm{m}^{-3}$ for the NLC mode and of $\sim 12 \mathrm{ng} \mathrm{m}^{-3}$ (with a broader peak) for the MUA modes (see Figs. 4a and b), which agree well with SOFIE data for the $2007 \mathrm{NH}$ season. As a result, the conclusion drawn by Hervig et al. (2009b) from SOFIE applies to the comparison of MIPAS with other measurements and models. That is, MIPAS ice mass densities are also significantly smaller than the lidar measurements taken at ALOMAR $\left(69^{\circ} \mathrm{N}\right)$, which show an average value of $47.4 \mathrm{ng} \mathrm{m}^{-3}$, and the lidar results reported by von Cossart et al. (1999), which show ice mass densities ranging from 36 to $102 \mathrm{ng} \mathrm{m}^{-3}$. These differences can be explained, at least partially, by the larger sensitivity of MIPAS (and SOFIE) to the smaller particles (i.e. being sensitive to smaller amounts leads to lower mean concentrations). Another reason causing the differences could be, at least for the lidar observations, the averaging over the relatively larger atmospheric volumes sampled by MIPAS (and SOFIE). Furthermore, MIPAS, as well as SOFIE, is also able to detect thinner ice clouds than other IR instruments measuring the PMCs from space, e.g. HALOE (Hervig et al., 2003).

Although a detailed comparison between MIPAS data and CARMA (Rapp and Thomas, 2006) has not been performed, the results reported by Hervig et al. (2009b) suggest that MIPAS and CARMA are in agreement, at least for the $65-75^{\circ}$ latitude range. A thorough comparison with the CARMA model and MIPAS data, including higher latitude regions, would be very useful but is beyond the scope of this paper. 

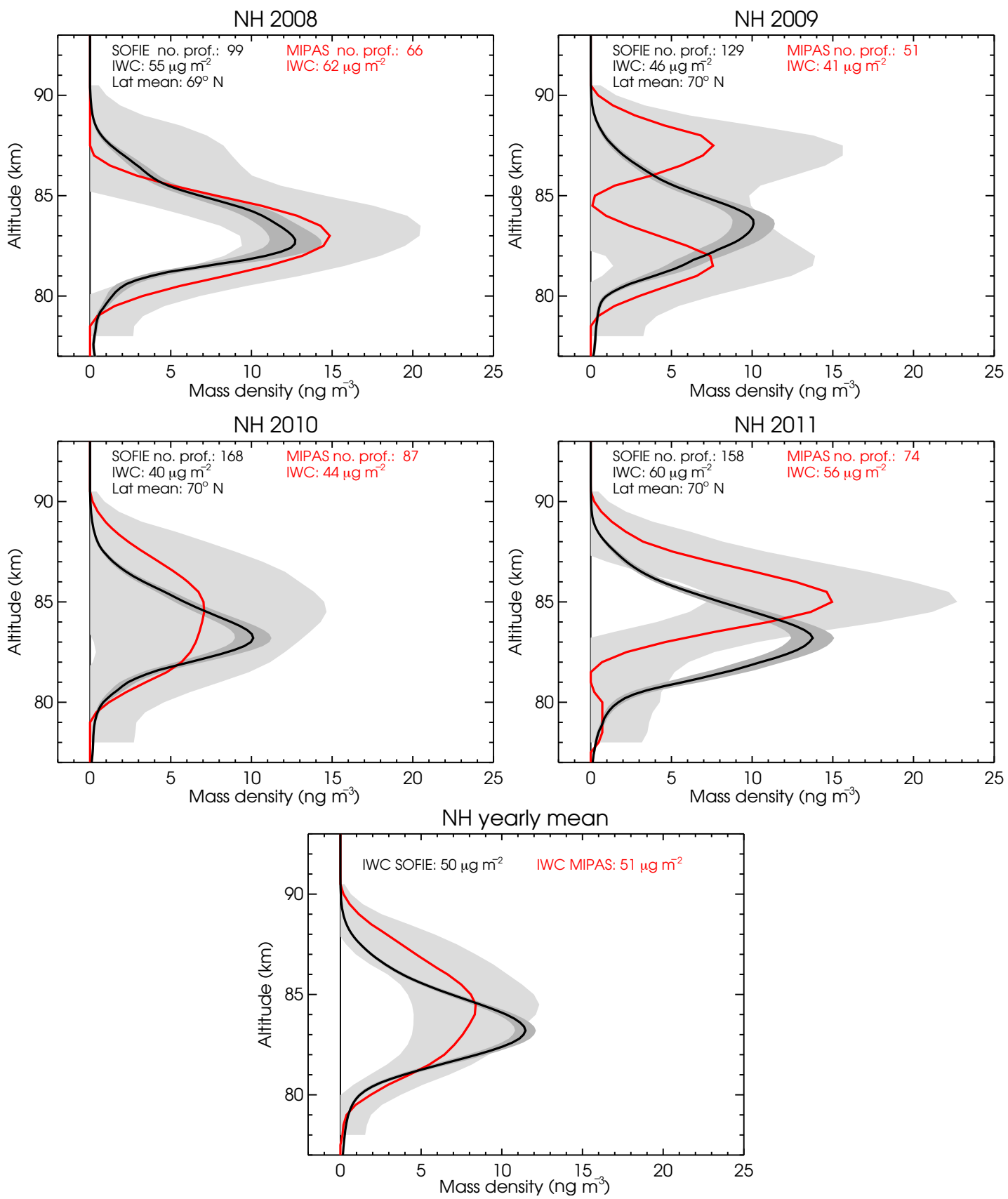

Figure 5. Comparison of the ice mass density of MIPAS MUA modes of measurements (see Table 1) with SOFIE v1.3 L2 data for the 2008 to 2011 period and the yearly mean (lower panel) in the NH. The solid lines show the mean profiles, SOFIE in black and MIPAS in red. The shaded areas are the standard deviations divided by the square root of the number of profiles. The means of the IWC are also shown.

Figure 5 shows a more detailed comparison between MIPAS and SOFIE ice mass densities, $M_{\text {ice }}$, for the coincident days and latitudes (within \pm 2 degrees of SOFIE mean latitude) in the $\mathrm{NH}$ season for the years with more coincident data: 2008-2011. The variation of ice mass density with local time is important (see, e.g. Stevens et al., 2010, and Sect. 6 below). Since most of SOFIE measurements were taken at local times between 23 and $24 \mathrm{~h}$ in the $\mathrm{NH}$, we have taken only the evening MIPAS measurements (made at 22:00). The comparison is based on the mean profiles for all days of measurements for each season/year for each instrument because of the large variability of MIPAS ice mass density (see, e.g. Fig. 1). The solid black lines represent the mean of SOFIE measurements and the solid red line the mean MIPAS ice mass density. These figures show quite a good agreement between the two instruments for 2008 and 2010. For 2009 
and 2011, the peak values are also in good agreement but the vertical distributions are rather different. The average over the four years (bottom panel in Fig. 1) reflects that above about $85 \mathrm{~km}$, MIPAS values are generally larger than those measured by SOFIE and smaller below that altitude. Similar behaviour is also seen in the SH (not shown). This seems to be a clear characteristic of MIPAS measurements but absent in SOFIE. We do not have a plausible explanation for this difference. A possible reason could be a negative bias of MIPAS temperature at those altitudes/latitudes which would result in a higher ice mass density, but such a bias present only in these localized regions seems unlikely. Another reason could be that the averaging kernels are wider in the PMC upper region (see Fig. 5 in López-Puertas et al., 2009). Note also that this vertical zonal distribution of the ice density in MIPAS is consistent with the water vapour (gas phase) latitudinal distribution measured by MIPAS (see Fig. 10), since the depletion of water vapour near $60-70^{\circ} \mathrm{N}$ occurs at higher altitudes than near the North Pole.

The IWC of both instruments, which are reported in Fig. 5, are in very good agreement. In the case of MIPAS the values are only slightly larger. The mean IWC of the coincident days for the 2008-2011 period in the NH is $50 \mu \mathrm{g} \mathrm{m}^{-2}$ for SOFIE and $51 \mu \mathrm{g} \mathrm{m}^{-2}$ for MIPAS evening measurements (see bottom panel in Fig. 1). It is noteworthy that the NH MIPAS observations are in slightly better agreement than SOFIE with model calculations carried out by Hervig et al. (2009c) (see their Fig. 5d). The mean IWC values for the 2008-2011 period for the SH are $24 \mu \mathrm{g} \mathrm{m}^{-2}$ for SOFIE and $27 \mu \mathrm{g} \mathrm{m}^{-2}$ for MIPAS measurements including both morning and evening data taken at 10:00 and 22:00 (SOFIE measures between 01:00 and 03:00 in the $\mathrm{SH}$ ).

\section{$3.4 \quad Q_{\text {ice }}$}

We also show the zonal mean of ice volume density in Fig. 6 (similar to Fig. 3) but in units of ppmv, $Q_{\text {ice}}$; i.e. the partial concentration of water vapour if all the ice were to sublimate. For that conversion we used the pressure and temperature measured by MIPAS (García-Comas et al., 2014). As expected Fig. 6 shows the same general behaviour as discussed above for the volume density (Fig. 3). In NLC mode, which contains observations during the mid-season period, we note that the amount of water vapour in the form of ice ranges from 1 to $3 \mathrm{ppmv}$ at latitudes equatorwards of $70-75^{\circ}$, and reaches values up to 5-6 ppmv close to the poles. Again these values are in good agreement with SOFIE measurements. Hervig et al. (2015) have shown time series of SOFIE $Q_{\text {ice }}$ at the altitude of peak extinction for the 2007-2013 period for the Northern and Southern hemispheres (their Fig. 2). The $\mathrm{NH}$ mid-summer values range from 2 to $3.3 \mathrm{ppmv}$, which compare well with those shown in the right panels of Fig. 6 at the latitudes of SOFIE measurements, $\sim 66-74^{\circ} \mathrm{N}$. Similarly, for the SH they show values spanning from 1.5 to $2.5 \mathrm{ppmv}$, also in good agreement with those of MIPAS shown in the left panels of Fig. 6. This point is discussed further in Sect. 5.

\section{Altitude and column density of the PMCs}

Figure 7 shows the mean altitude of the PMC layer for the SH (left) and the NH (right) seasons for all measurements. The altitude of the PMC layer has been calculated as the altitude weighted with the 4 th power of the volume ice density. We observe that the mean altitude in the NH for the NLC mode is located around $83.5-84 \mathrm{~km}$, while in the $\mathrm{SH}$ it is about $1 \mathrm{~km}$ higher $(84.5-85 \mathrm{~km})$. The fact that the mean altitude is higher (in $\sim 1 \mathrm{~km}$ ) for the MA + UA modes is attributed to the coarser sampling and to the broader vertical resolution in the retrieved temperature from these modes. The different temporal sampling of the NLC and MUA modes might also have an effect. Hervig et al. (2013) have shown that PMCs are located higher at the beginning and end of the season, and lower in the middle of the season. This coincides with our results since the NLC-mode measurements are usually taken in the middle of the PMC season while MUA are taken earlier and later in the season. We should also note from Fig. 7 that PMCs tend to be located at lower altitudes near the poles, and at higher altitudes towards midlatitudes (both in $\mathrm{NH}$ and $\mathrm{SH}$ but more clearly in the latter).

Hervig et al. (2009b, 2013) reported an average value for the mean altitude of the PMC layer of $83.5 \mathrm{~km}$ for $\mathrm{NH}$ and $84.7 \mathrm{~km}$ for SH in SOFIE measurements, and of $83.3 \mathrm{~km}$ for the $\mathrm{NH}$ from concurrent lidar ALOMAR measurements in northern Norway $\left(69^{\circ} \mathrm{N}\right)$. The MIPAS mean values for the mean altitude obtained here for the $\mathrm{NH}$ is very close to both measurements. Also, it is very much in line with SOFIE, locating the maximum of the layer about $1 \mathrm{~km}$ higher in the $\mathrm{SH}$ than in the NH.

Russell et al. (2010) carried out a multi-year analysis of the Odin/OSIRIS, SNOE/UVS, AIM/SOFIE, and TIMED/SABER data sets in the polar regions northwards and southwards of $65^{\circ} \mathrm{N}\left({ }^{\circ} \mathrm{S}\right)$ and found that the mean PMC height is located $3.5 \mathrm{~km} \pm 0.5 \mathrm{~km}$ below the mean mesopause height. In the case of SOFIE measurements, however, this difference is significantly smaller, by $\sim 1 \mathrm{~km}$, for most of the season, except around the middle of the season (Russell et al., 2010). We also looked at the difference between the mean PMC height and the mean mesopause height in the MIPAS PMC measurements (see Fig. 7). In general MIPAS observations are more in line with SOFIE observations than with the other instruments. For the case of NLC and MUA MIPAS observation modes in the $\mathrm{NH}$ near $70^{\circ} \mathrm{N}$, the difference is about $2.5 \mathrm{~km}$, smaller than the mean value of $3.5 \mathrm{~km}$ obtained for all instruments and closer to the SOFIE value obtained by Russell et al. (2010). It is worth noting that this altitude difference increases towards the North Pole, more clearly in the case of the NLC mode (taken around the middle of the season) and reaching about $4 \mathrm{~km}$. In the Southern Hemisphere 

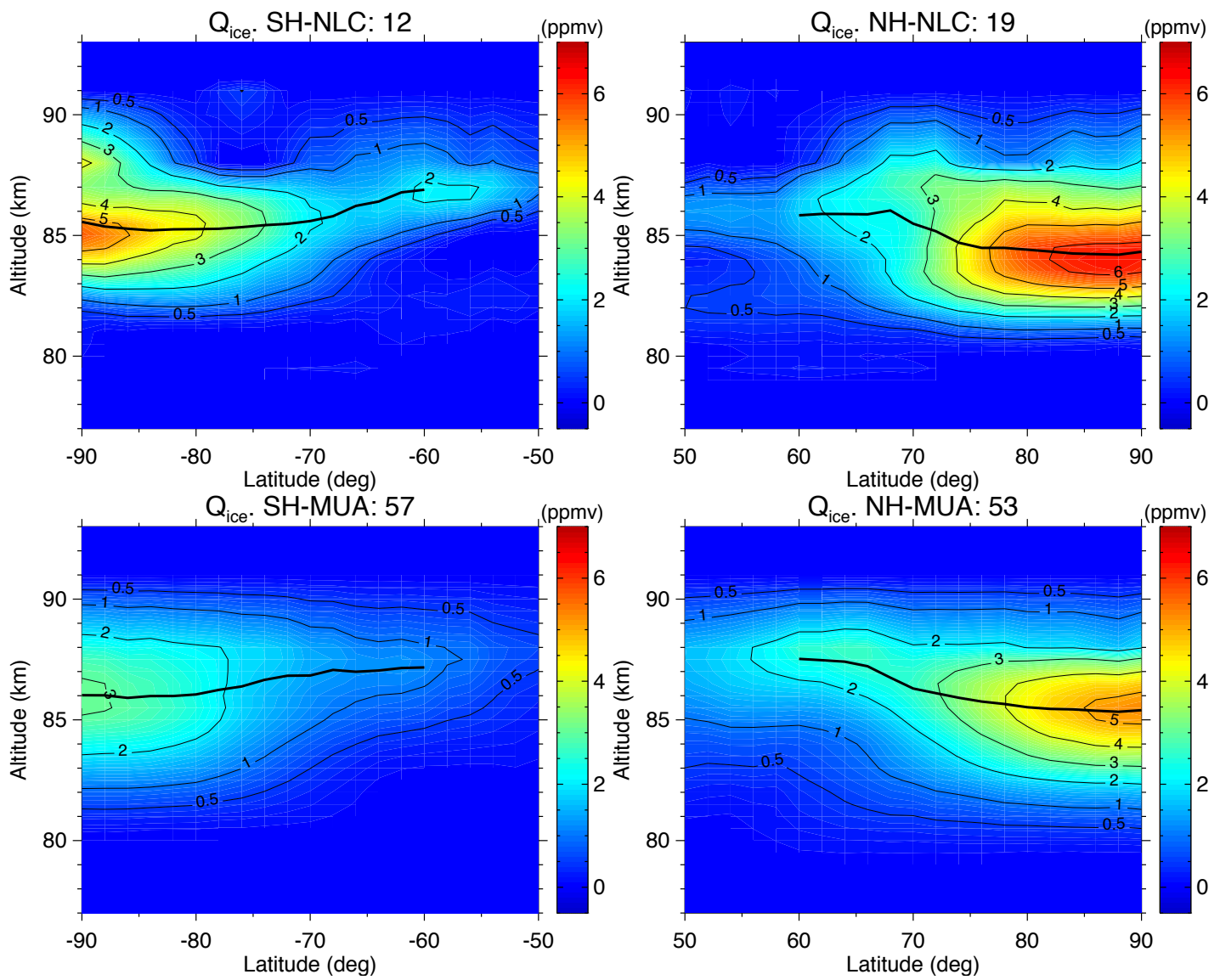

Figure 6. Same as Fig. 3 but in units of ppmv. The noise error of the $\mathrm{H}_{2} \mathrm{O}$ ice concentration plotted here, estimated by the standard error of the mean, is about 0.08 and 0.04 ppmv for the NLC and MUA measurements, respectively.
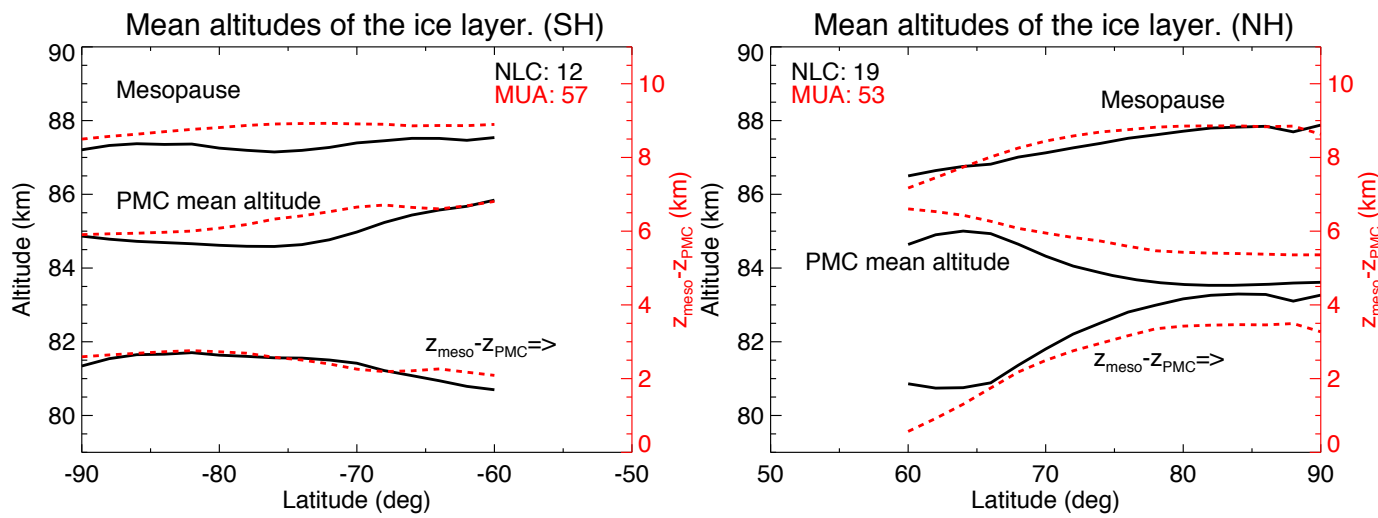

Figure 7. Mean altitudes of the mesopause ( $z_{\text {meso }}$ ), of the PMC layer (zPMC), and the difference $z_{\text {meso }}-z_{\mathrm{PMC}}$ (right $y$ axis) for the SH (left) and the NH (right) seasons for all measurements. The different colours indicate the results for the NLC (black) and MUA (red) MIPAS observation modes (see Table 2).

the difference between the mesopause and mean ice layer altitudes is even smaller than for $\mathrm{NH}$, with values ranging between 2 and $2.8 \mathrm{~km}$; again in better agreement with SOFIE than with the other instruments.
Figure 8 shows the latitudinal variation of the ice water content of the PMC layer for the SH (left) and the NH (right) seasons for all measurements. The figure shows clearly that PMCs are more abundant in the $\mathrm{NH}$ than in the $\mathrm{SH}$, extending to lower latitudes in the $\mathrm{NH}$. The main reason for 

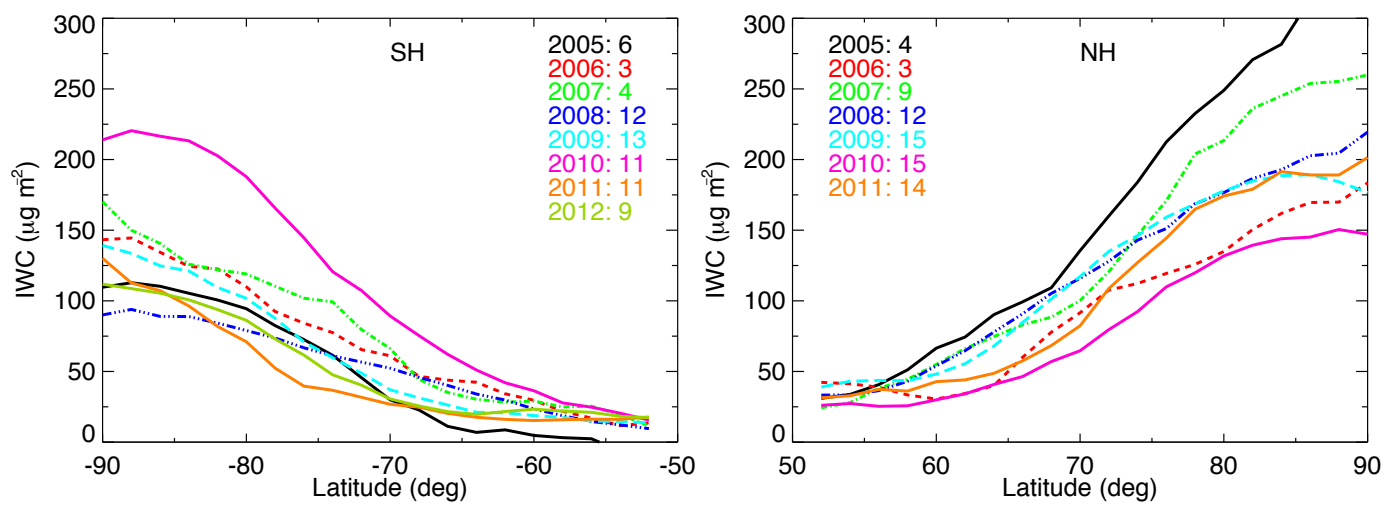

Figure 8. Latitudinal distribution of IWC of the PMC layers for the SH (left) and the NH (right) seasons for all measurements. The colours indicate the data for different years and the number of days measured per year (see Table 2).

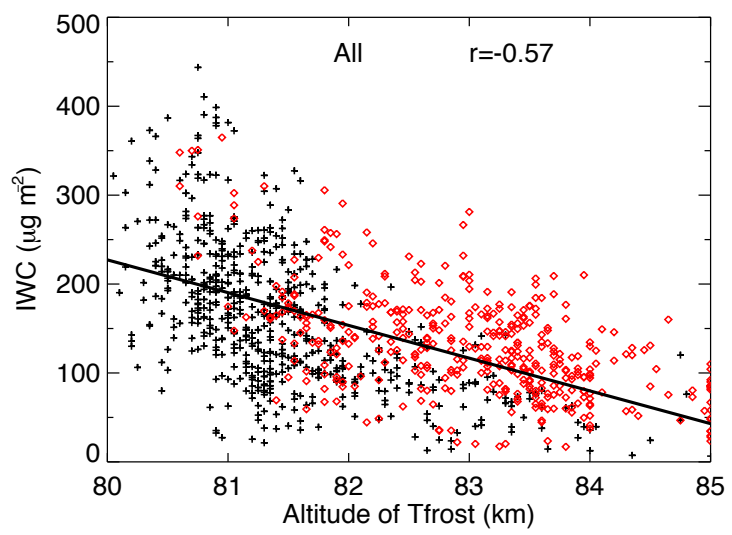

Figure 9. Correlation between IWC and the altitude of the lower branch of the frost-point temperature contour (see Fig. 1) for all data including the NLC+ MUA observation modes for the NH (black pluses) and SH (red diamonds) PMCs seasons (see Table 2). The black line is a linear fit to the data and $r$ the correlation coefficient.

this is the warmer polar upper mesosphere in the SH than in the $\mathrm{NH}$, about a $10 \mathrm{~K}$ difference as measured by MIPAS (García-Comas et al., 2014). Figure 8 is consistent with the zonal mean ice volume density shown in Fig. 3, which shows that ice mass density increases towards the poles. Large variability from season to season is also clearly visible, which in the case of MIPAS is attributable not only to the yearly changes but also to the daily variation because of the infrequent temporal sampling of MIPAS. The ice column is large for the NLC mode (not shown) in correspondence with the zonal mean fields shown in Fig. 3. As mentioned before, this is probably due to the fact that the NLC measurements are taken around the middle of the season (see Table 1). The $\mathrm{NH} / \mathrm{SH}$ ratio of the ice water content varies with latitude (not shown), ranging from about a factor of 2 near $60^{\circ}$ to 1.4 near the poles, with a value of 1.7 near $70^{\circ}$, which is in very good agreement with the factor of $65 \%$ reported by Hervig et al. (2013) from SOFIE measurements.
Figure 9 shows the correlation between the ice water content and the altitude of the lower branch of the frost-point temperature contour (see Fig. 1) for the data taken in the NLC and MUA observation modes in the SH and NH PMCs seasons. The correlation is significant and shows that the PMC layers contain more ice when the frost-point temperature occurs at lower altitudes. We have done the analysis for each hemisphere and mode separately (not shown) and found a very similar correlation for all cases except for the NLC mode in the NH. The reason for this exception could be the smaller sample size of this case or that the altitude range of the frost temperature in $\mathrm{NH}$ for this mode is very small and hardly reaches altitudes higher than $82 \mathrm{~km}$.

We have also found that the ice volume density is also anti-correlated with the mean altitude of the PMC layer (not shown), that is, that the denser PMC layers are located at lower altitudes and the thinner ones at higher altitudes. This is consistent with the behaviour shown in Figs. 7 and 8 where the denser layers are usually found near the poles and at lower mean altitudes.

\section{Correlation of ice volume density with $\mathrm{H}_{2} \mathrm{O}$ concentration}

Hervig et al. (2015) suggest that, as opposed to HALOE and MLS water vapour measurements, the SOFIE vertical resolution is well suited for the study of correlations between water ice and water vapour. This is also the case for MIPAS. Given the good latitudinal coverage of MIPAS (covering the whole polar region) and the fact that the instrument is able to measure the ice water content and the water vapour concentration simultaneously, we have looked at the zonal mean as well as latitudinal and longitudinal distribution of both quantities in the polar summer region.

The water vapour concentrations used here have been derived from MIPAS high-resolution spectra in the region around $6.3 \mu \mathrm{m}$. We used version v5r_h2o_M22 retrievals. 

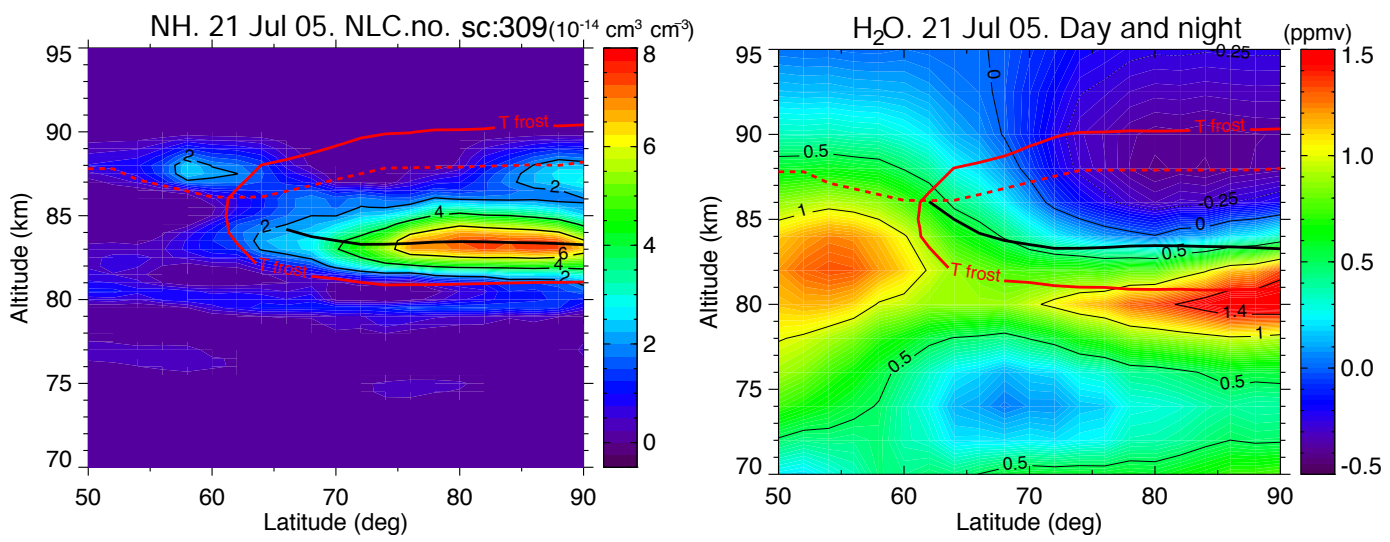

Figure 10. Zonal mean ice volume density (left) and of $\mathrm{H}_{2} \mathrm{O}$ concentration anomaly (the mean profile has been subtracted) (right) for 21 July 2005. The solid red lines indicate the frost-point temperature. The red dashed line is the mesopause as measured from MIPAS. The solid black line is an estimated mean altitude of the PMC layer (see Sect. 4).

The retrieval baseline is an extension to the lower mesosphere of the set-up described by Milz et al. (2005) with the updates described by von Clarmann et al. (2009). The main difference of this extension is the inclusion of non-LTE emissions from the $\mathrm{H}_{2} \mathrm{O}$ vibrational levels, which are important above around $50 \mathrm{~km}$ (Stiller et al., 2012). Additional microwindows, covering stronger $\mathrm{H}_{2} \mathrm{O} v_{2}$ spectral lines, are also included in order to increase the sensitivity in the upper mesosphere (García-Comas et al., 2012b).

Figure 10 shows a typical case (21 July 2005) of the zonal mean cross sections of the ice volume density (left) and the $\mathrm{H}_{2} \mathrm{O}$ concentration anomaly (right). We can clearly distinguish three distinct altitude zones near the polar region: a region centred near the peak of the PMC layer $(\sim 83 \mathrm{~km})$, where the ice volume density is largest; a hydrated region a few kilometres below, where $\mathrm{H}_{2} \mathrm{O}$ presents a relative maximum at latitudes northwards of $70^{\circ} \mathrm{N}$, more markedly seen in the bottom panel of Fig. 11; and a dehydrated region above the ice layer around $\sim 90 \mathrm{~km}$, where $\mathrm{H}_{2} \mathrm{O}$ exhibits a clear relative minimum (see top panel of Fig. 11). This global behaviour fits very well with the current picture we have of the PMCs, where sequestration of $\mathrm{H}_{2} \mathrm{O}$ in the gas phase to form ice leads to a drier atmosphere just above the ice layer, and where the sedimentation of ice and its subsequent sublimation enhances the $\mathrm{H}_{2} \mathrm{O}$ gas-phase abundance at $\sim 80 \mathrm{~km}$. The MIPAS water vapour layered structure gets sharper towards the pole. This is in contrast to findings from von Zahn and Berger (2003), who located the maximum at about $70^{\circ} \mathrm{N}$.

These features are more clearly observed in the latitude/longitude maps (Fig. 11), where the dry region at $90 \mathrm{~km}$ (top), the water ice layer at $83 \mathrm{~km}$ (middle), and the wetter $\mathrm{H}_{2} \mathrm{O}$ region at $80 \mathrm{~km}$ (bottom) are all well confined to the polar region. This topic has been recently studied quantitatively by Hervig et al. (2015) using SOFIE observation of ice content, water vapour, and temperature at latitudes near $70^{\circ}$. They found that, in both hemispheres, the altitude of the peak of the dehydration regions is $\sim 1.8 \mathrm{~km}$ above the height of peak ice mass density, and the altitude of the peak of the hydration region is $\sim 0.3 \mathrm{~km}$ above the observed bottom of the ice layer. Although no general conclusion can be drawn from the single day of MIPAS data shown here, we have found different results. In MIPAS the peak altitude of the hydration region is about $1 \mathrm{~km}$ below the bottom altitude of the PMC layer, and the dehydration region is found to be significantly (about $2-3 \mathrm{~km}$ ) higher than in SOFIE (see right panel in Fig. 10).

Hervig et al. (2015) also found that the column abundance of $\mathrm{H}_{2} \mathrm{O}$ in the gas phase is roughly equal in the dehydration and hydration regions, but less than that contained in the ice layer. From the day of MIPAS data analysed here we find that the excess of $\mathrm{H}_{2} \mathrm{O}$ gas-phase column in the hydration region ranges from 5.5 to $9 \mathrm{ppmv} \times \mathrm{km}$ for $70-90^{\circ} \mathrm{N}$, while the column of the upper drier region is significantly smaller, ranging from -1 to $-4.5 \mathrm{ppmv} \times \mathrm{km}$. We should note, however, that we use the mean $\mathrm{H}_{2} \mathrm{O}$ gas profile averaged over all latitudes as the "background", which could probably partially explain the differences with SOFIE. MIPAS and SOFIE, however, agree very well in that the excess and deficit $\mathrm{H}_{2} \mathrm{O}$ gas-phase concentrations are significantly much smaller than those contained in the ice cloud. Figure 10 shows MIPAS-enhanced values of about $1.5 \mathrm{ppmv}$ in the hydration layer and a decrease of $0.5 \mathrm{ppmv}$ in the dehydration region, while the $Q_{\text {ice }}$ peak is about 6 ppmv. A more comprehensive study using all MIPAS data should, however, be carried out to confirm these findings.

\section{Diurnal variation of ice volume density}

The diurnal variation of PMCs is an important factor to be taken into account when comparing data sets with different temporal sampling. Several studies have shown that the IWC may have a significant diurnal variation at latitudes close to 

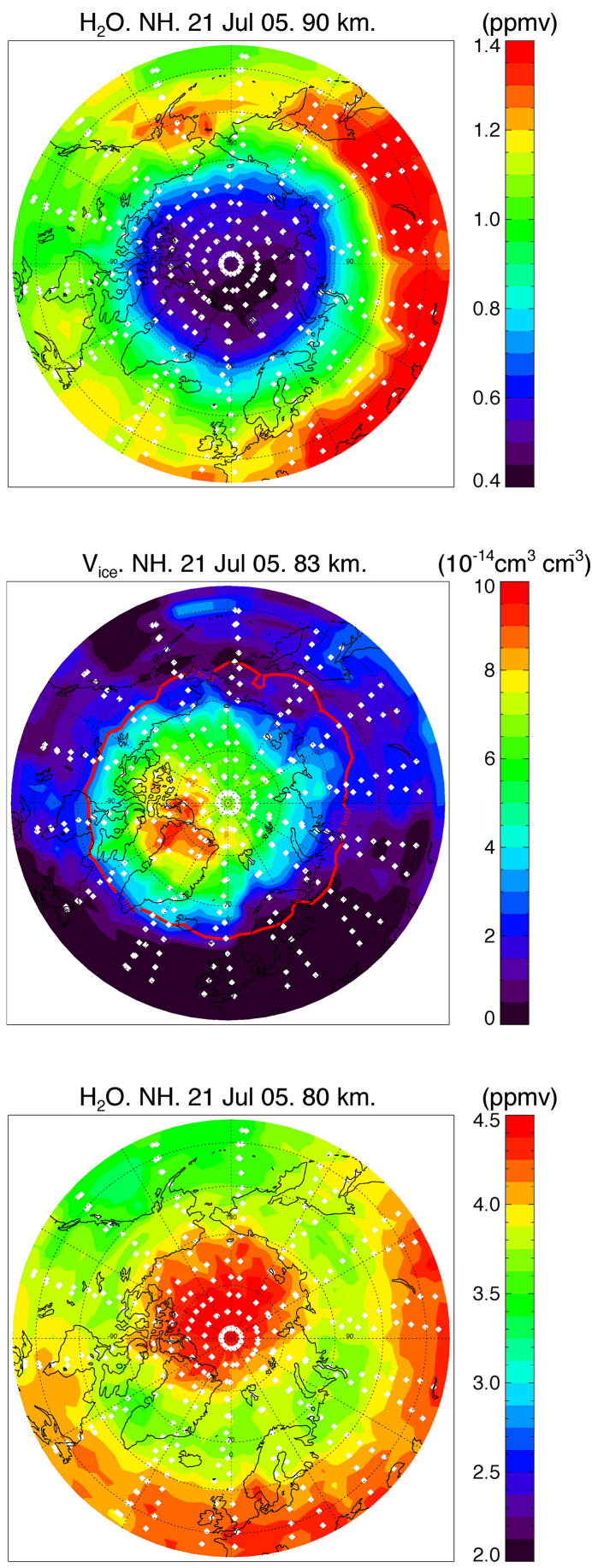

Figure 11. Polar maps of $\mathrm{H}_{2} \mathrm{O}$ vmr for altitudes of $90 \mathrm{~km}$ (top) and $80 \mathrm{~km}$ (bottom) (note the different scales) and of ice volume density at $83 \mathrm{~km}$ (middle panel) for 21 July 2005 (see Fig. 10). The white diamonds represent the geolocations of MIPAS measurements.

and equatorwards of $70^{\circ}$, mainly driven by tidal effects in temperature and in meridional advection at subpolar latitudes (Stevens et al., 2010; Gerding et al., 2013). MIPAS measures PMCs at two local times, 10:00 and 22:00, and hence easily allows for the inspection of variations due to the diurnal migrating tide (see García-Comas et al., 2016). Figure 12 shows the absolute (upper panels) and relative (middle panels) zonal mean differences (morning-evening) of MIPAS ice volume density averaged over all measurements in the SH (left panels) and NH (right panels).

The morning-evening absolute differences are larger in the $\mathrm{NH}$, partially due to the larger concentrations in this hemisphere. The relative differences in the $\mathrm{NH}$ are larger at $60-80^{\circ} \mathrm{N}$, and reach a maximum value of $0.75 \times 10^{-14} \mathrm{~cm}^{3} \mathrm{~cm}^{-3}$. The morning enhancement is in line with the predictions of Stevens et al. (2010) but not as large as their calculated factor of 4-5 in the IWC at $69^{\circ} \mathrm{N}$. At this latitude, we find a maximum enhancement of about $80 \%$ in the volume density and $40-50 \%$ in the IWC (not shown). Note however that simulations by Stevens et al. (2010) correspond only to June 2007. The changes in the ice volume density at $65-75^{\circ} \mathrm{N}$ shown in Fig. 12 result in the MIPAS NH evening clouds being on average at slightly lower altitudes, also in agreement with Stevens et al. (2010).

The morning-evening difference of ice volume density at $50-60^{\circ} \mathrm{N}$ is $0.25-0.5 \times 10^{-14} \mathrm{~cm}^{3} \mathrm{~cm}^{-3}$ at $81-87 \mathrm{~km}$, i.e. morning / evening ratios lying between 1.5 at $86 \mathrm{~km}$ and 7 at $82 \mathrm{~km}$ (Fig. 12). These changes result in narrower and thinner evening clouds, on average, that mainly disappear below $84 \mathrm{~km}$, in agreement with findings at subpolar latitudes from Stevens et al. (2010) and Gerding et al. (2013). The IWC morning / evening ratio increases rapidly towards these lower latitudes and varies in the range of 1.5 to 2.8 at 50$60^{\circ} \mathrm{N}$ (not shown).

The bottom panels of Fig. 12 correspond to 10:00-22:00 differences in the kinetic temperature measured by MIPAS simultaneously with the ice volume densities. These are a good measure of the temperature perturbations due to the diurnal migrating tide (García-Comas et al., 2016). The morning-evening ice volume density differences in the $\mathrm{NH}$ (right panels in Fig. 12) are generally anti-correlated with the corresponding morning-evening kinetic temperature differences. For example, the positive ice differences at $80-85 \mathrm{~km}$ equatorward of $80^{\circ} \mathrm{N}$ correspond to negative temperature differences. The temperature differences tend to be positive above $87 \mathrm{~km}$ northward of $65^{\circ} \mathrm{N}$, which is reflected in the ice volume density differences. Nevertheless, it is not possible to infer from these anti-correlations alone the extent to which diurnal temperature perturbations affect the ice volume density. Direct influence from other factors, like tidal variation of meridional advection (see, e.g. Gerding et al., 2013) or non-linear behaviour of phase transitions, cannot be ruled out.

Indeed, the anti-correlation between diurnal variation of the ice density (upper and middle left panels in Fig. 12) and that of temperature (lower left panel) in the SH is not so clear. In this hemisphere, the negative morning-evening temperature difference at $50-60^{\circ} \mathrm{S}$ and $80-84 \mathrm{~km}$ is weaker and located at lower altitudes than in the $\mathrm{NH}$. The corre- 

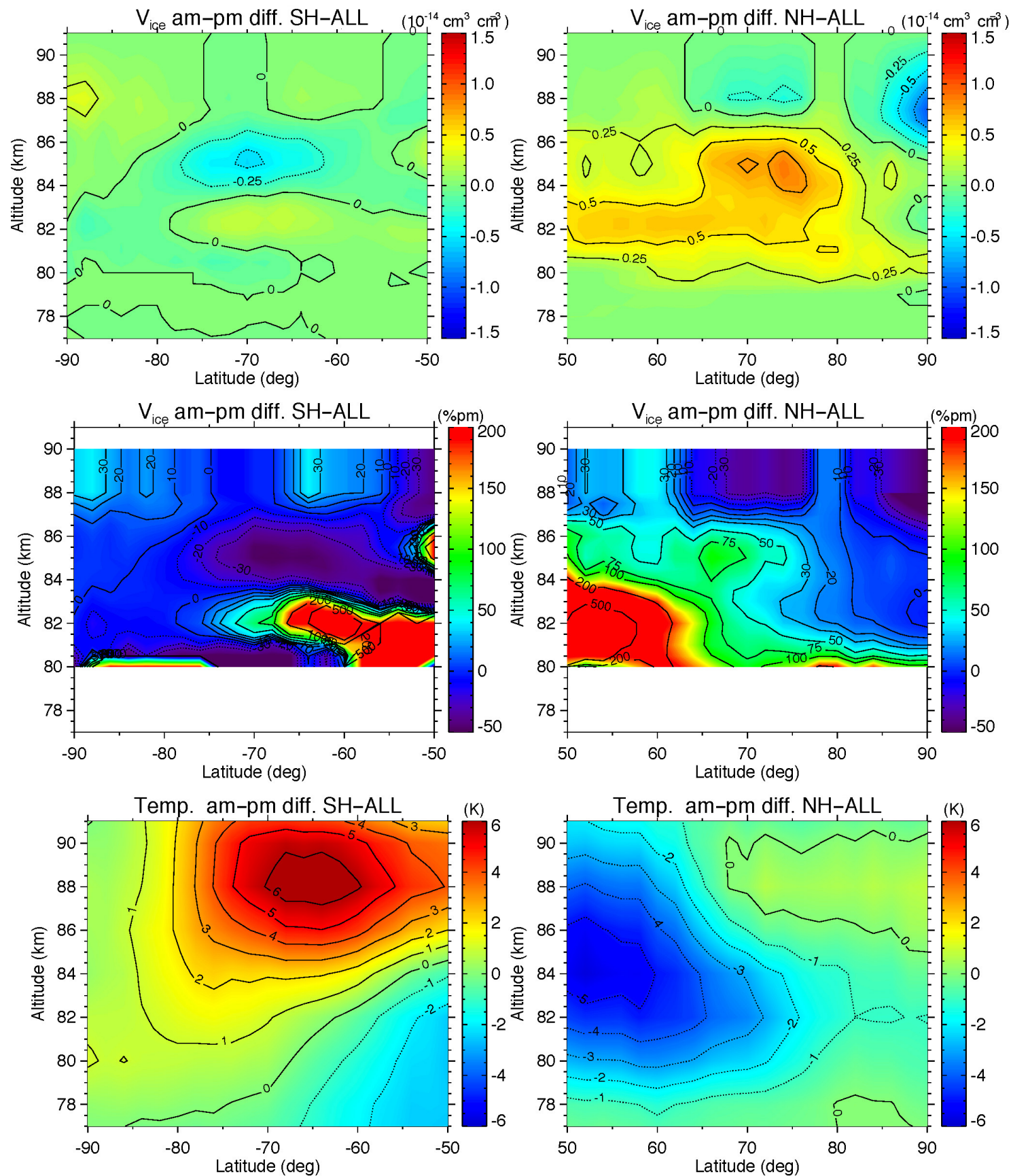

Figure 12. Top and middle panels: zonal mean morning-evening ice volume density differences (in absolute and \% of pm, respectively) for the SH (left) and NH (right). Bottom panels: zonal mean morning-evening temperature differences as measured by MIPAS for the SH (left) and $\mathrm{NH}$ (right).

sponding absolute diurnal ice change is small but the ice volume density at these latitudes is also very small (less than $5 \times 10^{-15} \mathrm{~cm}^{3} \mathrm{~cm}^{-3}$ ). The negative ice concentration difference at $84-88 \mathrm{~km}$ corresponds to a positive temperature difference but only at $60-80^{\circ} \mathrm{S}$. And most strikingly, the morning-evening temperature perturbation around 80 $84 \mathrm{~km}$ at $65-80^{\circ} \mathrm{S}$ is positive but so is the ice variation. This indicates that a diurnally varying driver other than temperature more significantly affects the diurnal ice variation at those latitudes, at least below $84 \mathrm{~km}$. The overall effect on ice density results in vertically alternating positive and negative changes that lead to lower SH morning mean cloud altitude. The impact of that driver most likely depends on altitude and 
latitude. A deeper analysis involving wind fields is beyond the scope of this paper and will be the focus of a future study.

\section{Conclusions}

We have analysed MIPAS IR measurements of PMCs for the NH and SH summer seasons from 2005 to 2012. PMCs were measured in the middle IR in emissions where, due to the small particle size, the signal is only affected by absorption and not by scattering. MIPAS is therefore sensitive to the total ice volume, including the very small ice particles that UV-VIS scattering observations are generally not sensitive to. The measurements cover only a few days of the PMC season (varying from 3 to 15) but have global pole-to-pole coverage. In this way, MIPAS measurements show, for the first time, global latitudinal coverage (from $50^{\circ}$ to the pole) of the total ice volume density.

MIPAS measurements indicate mesospheric ice existing as a continuous layer extending from about $\sim 81 \mathrm{~km}$ up to about $88-89 \mathrm{~km}$ on average and from the poles to about $55-60^{\circ}$ in each hemisphere. These altitudes are in very good agreement with SOFIE measurements, with the lowest altitude being slightly lower $(\sim 0.7 \mathrm{~km})$ in MIPAS, and the uppermost altitude slightly higher $(1.7 \mathrm{~km})$, probably caused by the wider MIPAS field of view. This bottom altitude is also slightly lower than that derived from lidar measurements but the uppermost altitude is significantly higher ( $4-5 \mathrm{~km}$ on average). This indicates that both MIPAS and SOFIE instruments are sensing the small ice particles in the upper part of the PMC layer. This has also been proved recently by the concurrent observations from the ALOMAR wind (ALWIN) radar and measurements from SOFIE (Hervig et al., 2011).

PMCs are very variable, both in space and time. On average, MIPAS measurements show that ice mass density increases towards the poles. The IWC measured by MIPAS at latitudes where SOFIE measurements are available show a good overall agreement, being in general slightly larger $(\sim 10 \%)$, and also exhibiting a larger variability, probably caused by the smaller sensitivity of MIPAS. A distinctive feature, however, is that in general MIPAS shows larger ice volume densities than SOFIE in the region above $\sim 85 \mathrm{~km}$ and smaller below.

The ice concentration is larger in the Northern Hemisphere than in the Southern Hemisphere. The ratio between the IWC in both hemispheres is also latitude-dependent, varying from a NH / SH ratio of 1.4 close to the poles to a factor of 2.1 around $60^{\circ}$. This also implies that PMCs extend to lower latitudes in the $\mathrm{NH}$.

We have found that the mean altitude of the PMC layer in the NH for the NLC mode of MIPAS observations is located around $83.5-84 \mathrm{~km}$, while in the $\mathrm{SH}$ it is about $1 \mathrm{~km}$ higher $(84.5-85 \mathrm{~km})$. This hemispheric asymmetry is in very good agreement with SOFIE observations (Hervig et al., 2013). For those MIPAS observations taken in the middle- and upper- atmosphere modes, the mean altitude is higher (by $\sim 1 \mathrm{~km}$ ). This difference is attributed to the coarser sampling and to the broader vertical resolution (particularly in the retrieved temperature) and also to the different temporal sampling of the modes since the NLC-mode measurements are usually taken in the middle of the PMC season while MUAmode observations are taken earlier and later in the season. A very clear feature in MIPAS observations is that PMCs tend to be at higher mean altitudes towards lower latitudes (in both hemispheres), particularly equatorwards of $70^{\circ}$.

MIPAS observations show that the difference between the mean PMC height and the mean mesopause height is about $2.5 \mathrm{~km}$ in the $\mathrm{NH}$ near $70^{\circ} \mathrm{N}$. This is smaller than the mean value of $3.5 \mathrm{~km}$ obtained from several satellite instruments by Russell et al. (2010) and closer to the SOFIE value (Hervig et al., 2013). MIPAS also shows that this altitude difference increases towards the North Pole, reaching a value close to $4 \mathrm{~km}$. In the Southern Hemisphere this difference is smaller than for the $\mathrm{NH}$, with values ranging between 2 and $2.8 \mathrm{~km}$; again the agreement with SOFIE is better than that with other instruments.

The anti-correlation between the ice water content and the altitude of the lower branch of the frost-point temperature contour is significant in MIPAS observations and shows that the PMC layers have larger ice mass densities when the frostpoint temperature occurs at lower altitudes. The simultaneous observations of MIPAS PMCs and water vapour have confirmed that PMC layers are surrounded by a hydrated region below and a dehydrated region above. These regions are more pronounced towards the poles, particularly at latitudes poleward of $70^{\circ} \mathrm{N}$. This global behaviour fits very well with the current picture we have of the PMCs, where sequestration of $\mathrm{H}_{2} \mathrm{O}$ in the gas phase to form ice leads to a drier atmosphere just above the ice layer and where the sedimentation of ice and its subsequent sublimation enhances the $\mathrm{H}_{2} \mathrm{O}$ gasphase abundance at $\sim 80 \mathrm{~km}$. The analysis of a single day of water vapour and PMCs measurements of MIPAS has shown different results than for SOFIE. The peak altitude of the hydration region is about $1 \mathrm{~km}$ below the bottom altitude of the PMC layer in MIPAS, while in SOFIE it is $\sim 0.3 \mathrm{~km}$ above (Hervig et al., 2015), and the dehydration region is found to be at $\sim 2-3 \mathrm{~km}$ above the height of peak ice mass density in MIPAS but $\sim 1.8 \mathrm{~km}$ in SOFIE. Further, MIPAS shows that the column abundance of water vapour excess in the hydration layer is about twice than the deficit in the dehydration layer near $70^{\circ} \mathrm{N}$, while they are very similar in SOFIE. However, they both agree that both quantities are much smaller than the water content in the form of ice.

Finally, MIPAS observations, which are taken at 10:00 and 22:00, also show a diurnal variation in the ice volume density. The IWC is larger at in the morning than in the evening in the $\mathrm{NH}$, in line with the model predictions of Stevens et al. (2010). This diurnal variation is anti-correlated with corresponding differences in temperature in the $\mathrm{NH}$, suggesting that it is driven by the temperature-migrating diurnal tide, 
but effects from other factors cannot be ruled out. In the $\mathrm{SH}$, the lack of a clear anti-correlation with temperature points to a significant impact of an additional driver.

Acknowledgements. We thank Patrick Espy for useful discussions about the temperature of the ice particles, and Stefan Lossow and two anonymous reviewers for very useful comments and suggestions. We thank the SOFIE team for providing data, taken from http://sofie.gats-inc.com/sofie/index.php. The IAA team was supported by the Spanish MICINN under the project ESP201454362-P and EC FEDER funds. MGC was financially supported by the MINECO under its "Ramón y Cajal" sub-programme.

Edited by: F.-J. Lübken

\section{References}

Bailey, S. M., Merkel, A. W., Thomas, G. E., and Carstens, J. N.: Observations of polar mesospheric clouds by the Student Nitric Oxide Explorer, J. Geophys. Res., 110, D13203, doi:10.1029/2004JD005422, 2005.

Baumgarten, G. and Fiedler, J.: Vertical structure of particle properties and water content in noctilucent clouds, Geophys. Res. Lett., 35, L1081, doi:10.1029/2007GL033084, 2008.

Berger, U. and Lübken, F.-J.: Trends in mesospheric ice layers in the Northern Hemisphere during 1961-2013, J. Geophys. Res., 120, 11277-11298, doi:10.1002/2015JD023355, 2015.

Berger, U. and von Zahn, U.: Three-dimensional modeling of the trajectories of visible noctilucent cloud particles: An indication of particle nucleation well below the mesopause, J. Geophys. Res., 112, D16204, doi:10.1029/2006JD008106, 2007.

Berger, U. and von Zahn, U.: Icy particles in the summer mesopause region: Three-dimensional modeling of their environment and two-dimensional modeling of their transport, J. Geophys. Res., 107, 1366, doi:10.1029/2001JA000316, 2002.

DeLand, M. T. and Thomas, G. E.: Updated PMC Trends Derived from SBUV Data, J. Geophys. Res., 120, 2140-2166, doi:10.1002/2014JD022253, 2015.

DeLand, M. T., Shettle, E. P., Thomas, G. E., and Olivero, J. J.: Solar bachscattered ultraviolet (SBUV) observations of polar mesospheric clouds (PMCs) over two solar cycles, J. Geophys. Res., 108, 8445, doi:10.1029/2002JD002398, 2003.

De Laurentis, M.: Planning of MIPAS new special modes January 2005 Campaign, Tech. rep., ESA Technical Note, ENVI-SPPAEOPG-TN-05-0002, 2005.

Espy, P. and Jutt, H.: Equilibrium temperature of water-ice aerosols in the high-latitude summer mesosphere, J. Atmos. Sol.-Terr. Phys., 64, 1823-1832, 2002.

Fiedler, J., Baumgarten, G., and Lübken, F.-J.: NLC observations during one solar cycle above ALOMAR, J. Atmos. Sol.-Terr. Phys., 71, 424-433, 2009.

Fischer, H., Birk, M., Blom, C., Carli, B., Carlotti, M., von Clarmann, T., Delbouille, L., Dudhia, A., Ehhalt, D., Endemann, M., Flaud, J. M., Gessner, R., Kleinert, A., Koopman, R., Langen, J., López-Puertas, M., Mosner, P., Nett, H., Oelhaf, H., Perron, G., Remedios, J., Ridolfi, M., Stiller, G., and Zander, R.: MIPAS: an instrument for atmospheric and climate research, Atmos. Chem. Phys., 8, 2151-2188, doi:10.5194/acp-8-2151-2008, 2008.

Funke, B., López-Puertas, M., García-Comas, M., Kaufmann, M., Höpfner, M., and Stiller, G. P.: GRANADA: a Generic RAdiative traNsfer AnD non-LTE population Algorithm, J. Quant. Spectrosc. Radiat. Transfer, 113, 1771-1817, doi:10.1016/j.jqsrt.2012.05.001, 2012.

Garcia, R., López-Puertas, M., Funke, B., Kinnison, D. E., Marsh, D. R., and Quian, L.: On the secular trend of $\mathrm{CO}_{x}$ and $\mathrm{CO}_{2}$ in the lower thermosphere, J. Geophys. Res., Atmos., 121, 3634-3644, doi:10.1002/2015JD024553, 2015.

García-Comas, M., Funke, B., López-Puertas, M., BermejoPantaleón, D., Glatthor, N., Clarmann, T. v., Stiller, G. P., Grabowski, U., Boone, C. D., French, W. J., Leblanc, T., LópezGonzález, M. J., and Schwartz, M.: On the quality of MIPAS kinetic temperature in the middle atmosphere, Atmos. Chem. Phys., 12, 6009-6039, doi:10.5194/acp-12-6009-2012, 2012a.

García-Comas, M., Funke, B., López-Puertas, M., Lossow, S., Gabriele, S., von Clarmann, T., Glatthor, N., and Grabowski, U.: Measurements of Water Vapor Distribution in the Middle Atmosphere by MIPAS, in: Advances in Atmospheric Science and Applications, edited by ESA, vol. ATMOS 2012 Abstract Book, 8889, ESA, 2012b.

García-Comas, M., Funke, B., Gardini, A., López-Puertas, M., Jurado-Navarro, A., von Clarmann, T., Stiller, G. P., Kiefer, M., Boone, C. D., Leblanc, T., Marshall, B. T., Schwartz, M. J., and Sheese, P. E.: MIPAS temperature from the stratosphere to the lower thermosphere: Comparison of vM21 with ACE-FTS, MLS, OSIRIS, SABER, SOFIE and lidar measurements, Atmos. Meas. Tech., 7, 3633-3651, doi:10.5194/amt-7-3633-2014, 2014.

García-Comas, M., González-Galindo, F., Funke, B., Gardini, A., Jurado-Navarro, A. A., López-Puertas, M., and Ward, W. E.: MIPAS observations of longitudinal oscillations in the mesosphere and the lower thermosphere: Part 1. Climatology of oddparity daily frequency modes, Atmos. Chem. Phys. Discuss., doi:10.5194/acp-2015-1065, in review, 2016.

Gerding, M., Kopp, M., Hoffmann, P., Höffner, J., and Lübken, F.-J.: Diurnal variations of midlatitude NLC parameters observed by daylight-capable lidar and their relation to ambient parameters, Geophys. Res. Lett., 40, 6390-6394, doi:10.1002/2013GL057955, 2013.

Grossmann, K. U., Gusev, O., Assou, M. A., and Witt, G.: Spectral emission measurements of polar mesopheric clouds by CRISTA-2, J. Atmos. Solar-Terr. Phys., 68, 1781-1790, doi:10.1016/j.jastp.2006.01.014, 2006.

Gumbel, J. and Witt, G.: In situ measurements of the vertical structure of a noctilucent cloud, Geophys. Res. Lett., 25, 493-496, 1998.

Hervig, M. and Gordley, L. L.: Temperature, shape, and phase of mesospheric ice from Solar Occultation for Ice Experiment observations, J. Geophys. Res., 115, D15208, doi:10.1029/2010JD013918, 2010.

Hervig, M., Thompson, R. E., McHugh, M., Gordley, L. L., Russell III, J. M., and Summers, M. E.: First confirmation that water ice is the primary component of polar mesospheric clouds, Geophys. Res. Lett., 28, 971-974, 2001.

Hervig, M., McHugh, M., and Summers, M. E.: Water vapor enhancement in the polar summer mesosphere and its relation- 
ship to polar mesospheric clouds, Geophys. Res. Lett., 30, 2041, doi:10.1029/2003GL018089, 2003.

Hervig, M. E. and Stevens, M. H.: Interpreting the 35 year SBUV PMC record with SOFIE observations, J. Geophys. Res., 119, 12689-12705, doi:10.1002/2014JD021923, 2014.

Hervig, M. E., Gordley, L. L., Russell, III, J. M., and Bailey, S. M.: SOFIE PMC observations during the northern summer of 2007, J. Atmos. Sol.-Terr. Phys., 71, 331-339, 2009a.

Hervig, M. E., Gordley, L. L., Stevens, M. H., Russell, III, J. M., Bailey, S. M., and Baumgarten, G.: Interpretation of SOFIE PMC measurements: Cloud identification and derivation of mass density, particle shape, and particle size, J. Atmos. Sol.-Terr. Phys., 71, 316-330, 2009b.

Hervig, M. E., Stevens, M. H., Gordley, L. L., Deaver, L. E., Russell, III, J. M., and Bailey, S. M.: Relationships between polar mesospheric clouds, temperature, and water vapor from Solar Occultation for Ice Experiment (SOFIE) observations, J. Geophys. Res., 114, D20203, doi:10.1029/2009JD01230, 2009c.

Hervig, M. E., Rapp, M., Latteck, R., and Gordley, L. L.: Observations of mesospheric ice particles from the ALWIN radar and SOFIE, J. Atmos. Sol.-Terr. Phys., 73, 2176-2183, 2011.

Hervig, M. E., Siskind, D. E., Stevens, M. H., and Deaver, L. E.: J. Atmos. Sol.-Terr. Phys., J. Atmos. Sol.-Terr. Phys., 104, 285 298, 2013

Hervig, M. E., Siskind, D. E., Bailey, S. M., and Russell, III, J. M.: The influence of PMCs on water vapor and drivers behind PMC variability from SOFIE observations, J. Atmos. Sol.-Terr. Phys., 132, 124-134, 2015.

López-Puertas, M., García-Comas, M., Funke, B., BermejoPantaleón, D., Höpfner, M., Grabowski, U., Stiller, G. P., von Clarmann, T., and von Savigny, C.: Measurements of polar mesospheric clouds in infrared emission by MIPAS/ENVISAT, J. Geophys. Res., 114, D00I07, doi:10.1029/2009JD012548, 2009.

Lübken, F.-J.: Thermal structure of the arctic summer mesosphere, J. Geophys. Res., 104, 9135-9150, doi:10.1029/1999JD900076, 1999.

Määttänen, A., Perot, K., Montmessin, F., and Hauchecorne, A.: Mesospheric Clouds on Mars and on Earth, in: Comparative climatology of terrestrial planets, edited by: J, M. S., Simo-Miller, A. A., Harder, J. W., Bullock, M. A., and Dotson, R., 393-413, University of Arizona Press, Tucson, Arizona, 2013.

Merkel, A. W., Thomas, G. E., Palo, S. E., and Bailey, S. M.: Observations of the 5-day planetary wave in PMC measurements from the Student Nitric Oxide Explorere Satellite, Geophys. Res. Lett., 30, 1196, doi:10.1029/2002GL016524, 2003.

Merkel, A. W., Rusch, D. W., Palo, S. E., Russell, III, J. M., and Bailey, S. M.: Mesospheric planetary wave effects on global PMC variability inferred from AIM-CIPS and TIMED-SABER for the northern summer 2007 PMC season, J. Atmos. Sol.-Terr. Phys., 71, 381-391, doi:10.1016/j.jastp.2008.12.001, 2009.

Milz, M., von Clarmann, T., Fischer, H., Glatthor, N., Grabowski, U., Höpfner, M., Kellmann, S., Kiefer, M., Linden, A., Mengistu Tsidu, G., Steck, T., Stiller, G. P., Funke, B., López-Puertas, M., and Koukouli, M. E.: Water Vapor Distributions Measured with the Michelson Interferometer for Passive Atmospheric Sounding on board Envisat (MIPAS/Envisat), J. Geophys. Res., 110, D24307, doi:10.1029/2005JD005973, 2005.

Nedoluha, G. E., Gomez, R. M., Hicks, B. C., Wrotny, J. E., Boone, C., and Lambert, A.: Water vapor measurements in the meso- sphere from Mauna Loa over solar cycle 23, J. Geophys. Res., 114, D23303, 12689-12705, 2009.

Nielsen, K., Siskind, D. E., Eckermann, S. D., Hoppel, K. W., Coy, L., McCormack, J. P., Benze, S., Randall, C. E., and Hervig, M. E.: Seasonal variation of the quasi 5 day planetary wave: Causes and consequences for polar mesospheric cloud variability in 2007, J. Geophys. Res.-Atmos., 115, D18111, doi:10.1029/2009JD012676, 2010.

Oelhaf, H.: MIPAS Mission Plan, ESA Technical Note ENVISPPA-EOPG-TN-07-0073, 2008.

O’Neil, R. R., Richards, E., Humphrey, C. H., and Stair, A. T.: Polar mesospheric clouds: Infrared measurements from the Midcourse Space Experiment, J. Geophys. Res., 113, A07303, doi:10.1029/2007JA012858, 2008.

Pérot, K., Hauchecorne, A., Montmessin, F., Bertaux, J.-L., Blanot, L., Dalaudier, F., Fussen, D., and Kyrölä, E.: First climatology of polar mesospheric clouds from GOMOS/ENVISAT stellar occultation instrument, Atmos. Chem. Phys., 10, 2723-2735, doi:10.5194/acp-10-2723-2010, 2010.

Perron, G., Aubertin, G., Desbiens, R., Fehr, T., Niro, F., Kleinert, A., Kiefer, M., Birk, M., and Wagner, G.: MIPAS Level 1b Algorithm Evolutions, in: ESA Living Planet Symposium 2010 (Bergen, Norway), vol. SP-686, ESA Publication Division, 2010.

Petelina, S., Llewellyn, E. J., Degenstein, D. A., and Lloyd, N. D.: Odin/OSIRIS limb observations of polar mesospheric clouds in 2001-2003, J. Atmos. Solar-Terr. Phys., 68, 42-55, doi:10.1016/j.jastp.2005.08.004, 2006.

Petelina, S. V. and Zasetsky, A. Y.: Temperature of mesospheric ice retrieved from the O-H stretch band, Geophys. Res. Lett., 36, L15804, doi:10.1029/2009GL038488, 2009.

Rapp, M. and Lübken, F.-J.: Polar mesosphere summer echoes (PMSE): review of observations and current understanding, Atmos. Chem. Phys., 4, 2601-2633, doi:10.5194/acp-4-2601-2004, 2004.

Rapp, M. and Thomas, G.: Modeling the microphysics of mesospheric ice particles: Assessment of current capabilities and basic sensitivities, J. Atmos. Sol.-Terr. Phys., 68, 715-744, 2006.

Raspollini, P., Carli, B., Ceccherini, S., Forzieri, G., Sgheri, L., Ridolfi, M., Carlotti, M., Papandrea, E., Arnone, E., Dinelli, B. M., Castelli, E., Remedios, J., Sembhi, H., Dudhia, A., Lopez-Puertas, M., Funke, B., Flaud, J.-M., von Clarmann, T., Hoepfner, M., Oelhaf, H., Fischer, H., Kiefer, M., Kleinert, A., Chipperfield, M., Perron, G., Aubertin, G., Birk, M., Wagner, G., Gessner, R., Mosner, P., Schmitt, M., Fehr, T., D’Alba, L., and Niro, F.: Level 2 near-real-time analysis of MIPAS measurements on ENVISAT, in: Eight years of MIPAS measurements, vol. SP-686, 011-d2, ESA Publication Division, 2010.

Roble, R. G. and Dickinson, R. E.: How will changes in carbon dioxide and methane modify the mean structure of the mesosphere and thermosphere?, Geophys. Res. Lett., 16, 1441-1444, 1989.

Rusch, D. W., Thomas, G. E., and Jensen, E. J.: Particle Size Distributions in Polar Mesospheric Clouds Derived From Solar Mesosphere Explorer Measurements, J. Geophys. Res., 96, 12,93312,939, 1991.

Russell, III, J. M., Rong, P., Bailey, S. M., Hervig, M. E., and Petelina, S. V.: Relationship between the summer mesopause and polar mesospheric cloud heights, J. Geophys. Res., 115, D16209, doi:10.1029/2010JD013852, 2010. 
Russell, III, J. M., Rong, P., Hervig, M. E., Siskind, D. E., Stevens, M. H., Bailey, S. M., and Gumbel, J.: Analysis of northern midlatitude noctilucent cloud occurrences using satellite data and modeling, J. Geophys. Res., 119, 3238-3250, 2014.

Russell III, J. M., Bailey, S. M., Gordley, L. L., Rusch, D. W., Horányi, M., Hervig, M. E., Thomas, G. E., Randall, C. E., Siskind, D. E., Stevens, M. H., Summers, M. E., Taylor, M. J., Englert, C. R., Espy, P. J., McClintock, W. E., and Merkel, A. W.: The Aeronomy of Ice in the Mesosphere (AIM) mission: Overview and early science results, J. Atmos. Sol.-Terr. Phys., 71, 289-299, 2009.

Stevens, M. H., Siskind, D. E., Eckermann, S. D., Coy, L., Mccormack, J. P., Englert, C. R., Hoppel, K. W., Nielsen, K., Kochenash, A. J., Hervig, M. E., Randall, C. E., Lumpe, J., Bailey, S. M., Rapp, M., and Hoffmann, P.: Tidally induced variations of polar mesospheric cloud altitudes and ice water content using a data assimilation system, J. Geophys. Res., 115, D18209, doi:10.1029/2009JD013225, 2010.

Stiller, G. P., von Clarmann, T., Funke, B., Glatthor, N., Hase, F., Höpfner, M., and Linden, A.: Sensitivity of trace gas abundances retrievals from infrared limb emission spectra to simplifying approximations in radiative transfer modelling, J. Quant. Spectrosc. Radiat. Transf., 72, 249-280, doi:10.1016/S00224073(01)00123-6, 2002.

Stiller, G. P., Kiefer, M., Eckert, E., von Clarmann, T., Kellmann, S., García-Comas, M., Funke, B., Leblanc, T., Fetzer, E., Froidevaux, L., Gomez, M., Hall, E., Hurst, D., Jordan, A., Kämpfer, N., Lambert, A., McDermid, I. S., McGee, T., Miloshevich, L., Nedoluha, G., Read, W., Schneider, M., Schwartz, M., Straub, C., Toon, G., Twigg, L. W., Walker, K., and Whiteman, D. N.: Validation of MIPAS IMK/IAA temperature, water vapor, and ozone profiles with MOHAVE-2009 campaign measurements, Atmos. Meas. Tech., 5, 289-320, doi:10.5194/amt-5-289-2012, 2012.

Thomas, G. E.: Are Noctilucent Clouds Harbingers of Global Change in the Middle Atmosphere?, Adv. Space Res., 32, 17371746, doi:10.1016/S0273-1177(03)00674-4, 2003.

Thomas, G. E., Olivero, J. J., Jensen, E. J., Schroeder, W., and Toon, O. B.: Relation between increasing methane and the presence of ice clouds at the mesopause, Nature, 338, 490, 1989.

Thomas, G. E., Thurairajah, B., Hervig, M. E., von Savigny, C., and Snow, M.: Solar-induced 27-day variations of mesospheric temperature and water vapor from the AIM SOFIE experiment: Drivers of polar mesospheric cloud variability, J. Atmos. Sol.Terr. Phys., 134, 56-68, 2015.

Tikhonov, A.: On the solution of incorrectly stated problems and method of regularization, Dokl. Akad. Nauk. SSSR, 151, 501$504,1963$.
Toon, O. B., Tolbert, M. A., Koehler, B. G., Middlebrook, A. M., and Jordan, J.: Infrared optical constants of $\mathrm{H}_{2} \mathrm{O}$ ice, amorphous nitric acid solutions, and nitric acid trihydrates, J. Geophys. Res., 99, 25631-25654, 1994.

von Clarmann, T., Glatthor, N., Grabowski, U., Höpfner, M., Kellmann, S., Kiefer, M., Linden, A., Mengistu Tsidu, G., Milz, M., Steck, T., Stiller, G. P., Wang, D. Y., Fischer, H., Funke, B., Gil-López, S., and López-Puertas, M.: Retrieval of temperature and tangent altitude pointing from limb emission spectra recorded from space by the Michelson Interferometer for Passive Atmospheric Sounding (MIPAS), J. Geophys. Res., 108, 4736, doi:10.1029/2003JD003602, 2003.

von Clarmann, T., Höpfner, M., Kellmann, S., Linden, A., Chauhan, S., Grabowski, U., Funke, B., Glatthor, N., Kiefer, M., Schieferdecker, T., , and Stiller, G. P.: Retrieval of temperature $\mathrm{H}_{2} \mathrm{O}, \mathrm{O}_{3}$, $\mathrm{HNO}_{3}, \mathrm{CH}_{4}, \mathrm{~N}_{2} \mathrm{O}$ and $\mathrm{ClONO}_{2}$ from MIPAS reduced resolution nominal mode limb emission measurements, Atmos. Meas. Tech., 2, 159-175, doi:10.5194/amt-2-159-2009, 2009.

von Cossart, G., Fiedler, J., and von Zahn, U.: Size distributions of NLC particles as determined from 3-color observations of NLC by ground-based lidar, Geophys. Res. Lett., 26, 1513-1516, 1999.

von Savigny, C. and Burrows, J. P.: Latitudinal variations of NLC particle radii derived from northern hemisphere SCIAMACHY/Envisat limb measurements, Adv. Space Res., 40, 765 771, doi:10.1016/j.asr.2006.12.032, 2007.

von Savigny, C., Petelina, S. V., Karlsson, B., Llewellyn, E. J., Degenstein, D. A., Lloyd, N. D., and Burrows, J. P.: Vertical variation of NLC particle sizes retrieved from Odin/OSIRIS limb scattering observations, Geophys. Res. Lett., 32, L07806, doi:10.1029/2004GL021982, 2005.

von Savigny, C., Robert, C., Bovensmann, H., Burrows, J. P., and Schwartz, M.: Satellite observations of the quasi 5-day wave in noctilucent clouds and mesopause temperatures, Geophys. Res. Lett., 34, L24808, doi:10.1029/2007GL030987, 2007.

von Zahn, U.: Are noctilucent clouds truly a "miners canary" of global change?, EOS Trans. AGU, 84, 261, 2003.

von Zahn, U. and Berger, U.: Persistent ice cloud in the midsummer upper mesosphere at high latitudes: Three-dimensional modeling and cloud interactions with ambient water vapor, J. Geophys. Res., 108, 8451, doi:10.1029/2002JD002409, 2003.

Yue, J., Russell, III, J. M., Jian, Y., Rezac, L., Garcia, R. R., LópezPuertas, M., and Mlynczak, M. G.: Increasing carbon dioxide concentration in the upper atmosphere observed by SABER, Geophys. Res. Lett., 42, 1-6, 2015. 